\title{
Evaluating Sustainable Product Alternatives by Combining Life Cycle Assessment with Full-cost Accounting: A Highway Guardrail Case Study
}

\author{
Adam A. Scouse, ${ }^{\mathrm{a}, *}$ Steven S. Kelley, ${ }^{\mathrm{a}}$ Richard A. Venditti, ${ }^{\mathrm{a}}$ and T. Eric McConnell ${ }^{\mathrm{b}}$ \\ Full-cost accounting techniques incorporate the environmental and \\ societal burdens a product generates through its manufacture, use, and \\ disposal into that product's price. This research generates full-cost prices \\ for functionally equivalent chromated copper arsenate (CCA) treated wood \\ and galvanized steel guardrail posts by combining previously conducted \\ life cycle inventory analyses results with secondary emission valuation \\ data. Based on the analysis, both CCA-treated posts and galvanized steel \\ posts have environmental damage costs associated with emissions \\ generated through the product's manufacturing, use, and disposal stages. \\ After developing full-cost prices for product alternatives, CCA-treated \\ wood guardrail posts were found to be a more economical and \\ environmentally responsible alternative to galvanized steel. In addition to \\ generating full-cost prices, this research uses Monte Carlo simulation to \\ provide estimates of variability around CCA-treated wood and galvanized \\ steel damage costs.
}

Keywords: Emission valuation; Environmental full-cost accounting; Impact pathway approach; Life cycle assessment; Shadow pricing

Contact information: a: Department of Forest Biomaterials, North Carolina State University, 2820

Faucette Drive, Raleigh, NC 27607 USA; b: Department of Forestry, Mississippi State University, Box

9680, Mississippi State, MS 39762 USA; *Corresponding author: aascouse@ncsu.edu

\section{INTRODUCTION}

Wood plays an important role in supporting U.S. infrastructure by meeting needs in construction, transportation, and energy industries. In addition to its valuable material properties, it is unique as the only domestically renewable material that can meet the nation's increased demand for these goods and services. However, wood is susceptible to weathering and biological deterioration from insects, mold, and fungi, which can cause the material to lose visual appeal, mechanical properties, and function. While there are naturally durable wood species, a wide array of wood preservation techniques have been developed to protect less durable wood from biotic damage (Morrell 2018). One of the most prevalent and effective preservative treatments is a mixture of chromated copper arsenate (CCA), which has been used extensively over the past 30 to 40 years.

CCA is a waterborne treatment that utilizes copper and arsenic as biocides, while the chromium facilitates the fixation of the copper and arsenic to wood cells (Lebow 2010). When applied properly at specified retention levels, CCA extends the service life of wood to approximately 40 years (Townsend et al. 2004). The wood preservation industry is estimated to have produced 650,199 cubic feet of treated wood products in 2019. The majority of that treated wood received water-borne treatments (approximately 79\%), of which CCA has an approximate $11 \%$ share (Smith 2020). Due to environmental concerns, 
the direct sale of CCA-treated wood to homeowners stopped in 2004. However, CCA is still specified and widely used in commercial applications (EPA 2016a). Wood preservation facilities are heavily concentrated in the U.S. Southeast due to the availability of southern yellow pine (SYP), a wood species with inherent properties favorable to preservative treatment. SYP makes up $76 \%$ of all treated wood species and $40 \%$ of SYP production goes on to be treated for applications such as utility poles, posts, and lumber. Major markets for treated wood products are construction, repair and remodeling, and industrial uses (Bailey 2003).

While treating wood with CCA extends its service life, it also generates environmental and social impacts during its manufacturing, use, and disposal. Preservative metals make their way into soil and groundwater at manufacturing facilities, during use, and represent a significant risk when disposed of in unlined landfills (Krietemeyer et al. 1997; Hingston et al. 2001; Townsend et al. 2003, 2005; Mercer and Frostick 2014). Laboratory leach rates for arsenic from preserved woods range between $3 \%$ and $68 \%$ and depend heavily upon test conditions, e.g., sample dimension, test type, exposure time, and soil pH (Townsend et al. 2004). Jones et al. (2019) estimate that CCA-treated wood products used in highway construction applications leach $46 \%, 21 \%$, and $48 \%$ of arsenic, chromium, and copper, respectively. In addition to environmental emissions, CCA-treated wood can be a human health risk via skin contact or by inhaling smoke during treated wood incineration (Ohgami et al. 2015; Yuntzu-Yen Chen and Olsen 2016). While it is clear that the metals used in wood preservation may be detrimental to environmental and human health under certain conditions, a myriad of factors determine the specific level of risk, including but not limited to, preservative loading rate, geographic site, soil conditions, weather, and human exposure.

While heavy metal leaching during treated wood product use is a concern, manufacturing the heavy metals, the wood product, and the wood treating process also generates negative impacts. Manufacturing the wood treatment chemicals requires mining heavy metals and transporting them to preservation manufacturing sites. This process generates significant amounts of particulate matter ten micrometers and smaller $\left(\mathrm{PM}_{10}\right)$, sulfur dioxide $\left(\mathrm{SO}_{\mathrm{x}}\right)$, and nitrogen oxides $\left(\mathrm{NO}_{\mathrm{x}}\right)$ (Bolin and Smith 2012). PM10, or inhalable particles, are a significant human health concern that create acute and chronic effects for respiratory and cardiovascular systems. Sulfur dioxide and nitrogen oxides, generated by fossil fuel combustion during metal ore extraction, also pose a threat to human respiratory systems and environmental health by contributing to acid rain formation and reducing visibility (EPA 2016b; EPA 2016c). In addition, forest thinning and harvest operations, raw material transportation, and manufacturing processes all require energy, much of which is produced by burning fossil fuels. However, the wood products industry is unique in that it frequently substitutes woody biomass in place of fossil fuels to satisfy energy demand in manufacturing processes (Miner 2010).

Damages to ecosystems and human health resulting from product manufacturing, use, and disposal represent a cost to society that is external to the perpetrator and is not included in the purchase price, i.e., not reflected in the current market structure. These unpriced negative side effects, called negative externalities, represent a form of market failure because there is no market incentive for reducing emissions (Nguyen et al. 2016). However, because people inherently value ecosystems and their personal health, these services should be included in the price. The U.S. has been successful in developing markets and prices for some aspects of environmental and human health by capping emissions and establishing emission trade permits for lead, $\mathrm{SO}_{\mathrm{x}}$, and $\mathrm{NO}_{\mathrm{x}}$. These programs 
have significantly contributed to national emission reductions and environmental policy goals (Ellerman et al. 2003). However, many pollutants and ecosystem services are not represented in these limited permit markets.

Outside of cap-and-trade markets, researchers have used multiple econometric methods to develop theoretical methods for pricing emissions. Shaik et al. (2002) investigated historical agricultural sector data from 1936 to 1997 to describe the environmental consequences of excess nitrogen application to Nebraska soils. Utilizing linear programming techniques, their analysis found that the cost of abating nitrogen pollution represented approximately $3 \%$ to $4 \%$ of farm revenue. Using a similar method, Bellver-Domingo et al. (2017) estimated the environmental costs resulting from excessive presence of pain relief and anti-epileptic medication in wastewater. Their study provided monetary values ranging from $€ 0.10$ to $€ 128.20$ per milligram of active ingredient and highlighted the significant cost differences between medication types and the different water sources into which they were being emitted. Radics et al. (2016) found that bioenergy production from woody biomass carried environmental costs ranging from $\$ 3.60$ to $\$ 4.50$ per million BTUs. Lastly, Tol's (2018) review of the economic impacts of climate change found that "a global mean temperature rise of $2.5^{\circ} \mathrm{C}$ would make the average person feel as if she had lost $1.3 \%$ of her income." These studies highlight the ways in which equilibrium pricing theory can be used to estimate the cost of environmental externalities in their respective research fields.

An alternative method for valuing emissions is the Impact Pathway Approach (IPA). The IPA framework was developed as part of the ongoing collaborate ExternE Project, which set out in 1991 with the goal of internalizing and valuing externalities to assist in energy policy decision making. The methodology is a result of over 15 years of collaborative research involving multiple European countries and organizations that represents one of the most comprehensive approaches to evaluating emission damage and abatement costs (Bickel and Friedrich 2005). The framework, outlined by Bruyn et al. (2010), provides four steps necessary to assign damage costs to pollutants.

Step one identifies geographically specific emission sources from a product system. To fulfill this requirement, it is often helpful to fall back on the life-cycle inventory (LCI) methodology, which defines a product system and its system boundary. The LCI generates a list of relevant inputs and outputs from each unit process. Step two investigates how those emissions are dispersed into the atmosphere, soil, or water and defines increases in emission concentration at receptor sites. Step three defines a dose-response function for each emissions as it pertains to human health and ecosystem, crop, and building damage. Lastly, step four assigns a monetary value to emission impacts on these categories based on stated or revealed preferences. By following these four steps, Bruyn et al. (2010) make a significant contribution to environmental and economic research literature by providing damage cost estimates for emissions taking place in Europe in the year 2008 using a 2.5\% discount rate. An in depth examination of the IPA methodology is provided by Bickel and Friedrich (2005).

With the ability to quantify the cost of externalities, it is then possible to examine product alternatives based on full-cost prices. This concept, called full-cost accounting (FCA), is a decision making tool similar to cost-benefit analysis or sustainability scorecards, which adjusts the existing price of a product or service by incorporating relevant indirect costs associated with negative environmental and social impacts. Since the mid-1990s, the U.S. Environmental Protection Agency (EPA) and oil, gas, chemical, and waste industries have used the FCA framework to make decisions based on the 
economic, environmental, and social pillars of sustainability. The advantage of the FCA approach is its ability to translate emissions outputs, which are often difficult to conceptualize, into easily understood monetary values (Jasinski et al. 2015).

Using any material or product includes inherent risks to human and ecosystem health. The magnitude of these risks can vary widely depending upon how that product is manufactured, used, and disposed, and may be poorly correlated with the price of the product. The product's impact can also vary widely based on the emissions it produces, e.g., particulate matter, chemical emissions, $\mathrm{SO}_{\mathrm{x}}$, or $\mathrm{NO}_{\mathrm{x}}$.

All of these issues apply to the production, use, and disposal of CCA-treated wood. However, they also apply to the production, use, and disposal of galvanized steel. Just like wood, galvanized steel also experiences deterioration over time and generates negative outputs related to its manufacture, use, and disposal. The negative emission outputs associated with galvanized steel are different and released in different quantities compared to treated wood. Outputs associated with steel manufacturing include anthropogenic carbon dioxide, $\mathrm{NO}_{\mathrm{x}}$, and $\mathrm{SO}_{\mathrm{x}}$ (Broadbent 2012).

The purpose of placing guardrails on roadsides is to reduce the severity of automobile accidents that take place near medians and embankments. In 2015 there were approximately 104,000 automobile accidents nationwide that involved collision with a guardrail, 909 of those resulted in fatalities (USDOT 2015). Since department of transportation construction budgets are constrained, installing functionally equivalent but more expensive guardrails means that less lineal feet of guardrail can be installed per dollar of funding. Bielenberg et al. (2014) found that wood and steel guardrail posts do provide functionally equivalent performance in full-scale crash tests and even suggests that weaker wood species like white pine could be substituted in lieu of SYP. This situation generates an opportunity cost as additional feet of installed guardrail could potentially reduce the total cost of traffic accidents over the product's service life. Incorporating the opportunity cost of uninstalled guardrails into the product's full-cost price would be challenging and is outside the scope of this study. However, doing so would be useful to determine whether the benefits of saved lives and reduced accident costs justify the damage costs associated with product manufacturing, use, and disposal.

\section{Study Goals}

The goals of this study are 1) demonstrate the use of FCA methodology that include the environmental and human health costs of externalities, and 2) compare CCA-treated wood posts to galvanized steel posts using full-cost accounting. This work uses LCI data to quantify relevant outputs associated with production, use, and disposal of CCA-treated wood and galvanized steel highway guardrail posts. Prices are assigned to these outputs based on emission valuation studies. This study provides a FCA price for the two products that incorporates the sales 'price' of production and the cost of negative environmental externalities. This study highlights the unintended consequences that arise when sustainability policy decisions are made without carefully and fully considering differing products' impact on humans and ecosystems. Choosing a product based on an incomplete understanding of the environmental concerns, without fully investigating relevant emissions and their resulting social and environmental impacts, may lead to unintended consequences that are ultimately counterproductive to overall sustainability goals.

This study's intended audience are students, researchers, consumers, and policy makers who are concerned about the impacts of product consumption on social, environmental, and economic well-being. This methodology should be of particular 
interest to those interested in valuating human health, ecosystem services, and other assets that are not clearly represented in current market structures.

\section{Study Scope}

This study evaluates full-cost prices for CCA-treated wood and galvanized steel highway guardrail posts (functional unit) using both cradle-to-gate and cradle-to-grave boundary conditions. Production systems studied in this work include raw material extraction, manufacturing, use, and end-of-life stages. For CCA-treated wood, the cradleto-grave boundary conditions includes extraction and production of the CCA treatment chemicals, forest harvesting, lumber manufacturing, guardrail post treating, and end-oflife. For galvanized steel, the cradle-to-grave boundary conditions include raw material extraction, steel post manufacturing, the hot dip galvanizing process, use, and end-of-life. For both systems, emissions associated with transportation are included in the life-cycle inventory. Given the significant differences in the alternatives for the end-of-life process, this work also conducted a cradle-to-gate analysis of both processes. For the CCA-treated wood, these alternatives include landfill with no leakage of CCA, landfill with partial leakage, and controlled or uncontrolled combustion. For the steel post, the end of life process assumed recycling, but the energy sources for recycling can vary widely by region.

\section{EXPERIMENTAL}

Guardrail posts serve as components of the overall guardrail system by anchoring guardrails into the ground. The functional unit used in this work was one highway guardrail post with an assumed service life of 40 years. The galvanized steel post dimension was defined as six feet long, having an $\mathrm{H}$ shape, and weighs 54 pounds. A standard wooden guardrail post dimension was defined as six feet long with a nominal cross section of $6 \times 8$ inches and weighed 80 pounds. Galvanized steel and treated wood guardrail posts are defined as functionally equivalent and interchangeable.

Elementary outputs from the production of CCA-treated wood and galvanized steel used in this analysis are provided by Bolin and Smith (2012) and the National Renewable Energy Laboratory (NREL 2012) and are summarized in "Emission" columns within Table 1 and Table 2. Bolin and Smith (2012) provides mid-point impact assessments for guardrail post alternatives based on TRACI impact categories.

Relevant assumptions for the CCA-treated guardrail post come from Bolin and Smith (2012) and are as follows. The wooden guardrail post preservative retention rate is 0.57 pounds per cubic foot, and all posts are assumed to meet the 40-year service life. While Smith (2013) recognizes that wooden guardrail posts experience variable decay in situ, it is reasonable to assert that wooden guardrail posts maintain structural integrity over the product's service life based on wood product treatment standards defined by the American Wood Protection Association (AWPA) and safety factors instituted during product design and testing. At the product's end-of-life, $10 \%$ of posts are assumed to be reused while $90 \%$ are disposed of in solid waste landfills. Wood carbon release in the landfill is allocated by $17 \%$ to carbon dioxide, $6 \%$ to methane, and $77 \%$ as long-term storage. Landfill methane produced by wood decay is modeled as being captured to generate electricity.

While Bolin and Smith's (2012) outputs are appropriately used in this analysis, it is worth noting in this context that the estimates of landfill fate assumed in this study are 
very conservative in nature. Disposed treated wood likely ends up in a modern dry landfill, where little degradation takes place; thus there would be little preservative leaching. Treated wood can also be disposed of in wet, lined landfills, which would prevent leaching preservatives from reaching groundwater. As a result, environmental damage costs related to methane, arsenic, and chromium presented in this work are likely overstated.

Table 1. LCl of Emissions for One CCA-Treated Wood Highway Guardrail Post

\begin{tabular}{|c|c|c|c|c|c|c|}
\hline Data Source & \multirow{2}{*}{\multicolumn{2}{|c|}{$\begin{array}{c}\text { NREL } 2012 \\
\text { Gate-to-qate }\end{array}$}} & \multicolumn{2}{|c|}{ Bolin et al. 2012} & \multicolumn{2}{|c|}{ Bolin et al. 2012} \\
\hline System Boundary & & & Cradle- & -gate & Cradle-t & grave \\
\hline & $\begin{array}{l}\text { Emission } \\
(\mathrm{kg})\end{array}$ & $\begin{array}{c}\text { Damage } \\
\text { cost }\end{array}$ & $\begin{array}{c}\text { Emission } \\
(\mathrm{kg})\end{array}$ & $\begin{array}{c}\text { Damage } \\
\text { cost }\end{array}$ & $\begin{array}{l}\text { Emission } \\
(\mathrm{kg})\end{array}$ & $\begin{array}{c}\text { Damage } \\
\text { cost }\end{array}$ \\
\hline $\mathrm{CO}_{2}-$ fossil & 0.24 & $\$ 0.01$ & 16.33 & $\$ 0.70$ & 23.59 & $\$ 1.00$ \\
\hline $\mathrm{CO}_{2}-$ non fossil & $\mathrm{N} / \mathrm{A}$ & $\mathrm{N} / \mathrm{A}$ & -46.266 & $-\$ 1.97$ & -35.380 & $-\$ 1.51$ \\
\hline Carbon monoxide & 0.001 & $\$ 0.00$ & 0.036 & $\$ 0.00$ & 0.039 & $\$ 0.00$ \\
\hline Ammonia & $\mathrm{N} / \mathrm{A}$ & $\mathrm{N} / \mathrm{A}$ & 0.000064 & $\$ 0.00$ & 0.000073 & $\$ 0.00$ \\
\hline Hydrochloric acid & $\mathrm{N} / \mathrm{A}$ & $\mathrm{N} / \mathrm{A}$ & 0.0017 & $\$ 0.00$ & 0.0032 & $\$ 0.01$ \\
\hline Hydrofluoric acid & $\mathrm{N} / \mathrm{A}$ & $\mathrm{N} / \mathrm{A}$ & 0.00016 & $\$ 0.00$ & 0.00034 & $\$ 0.00$ \\
\hline Nitrogen oxides & 0.001 & $\$ 0.02$ & 0.07 & $\$ 1.23$ & 0.09 & $\$ 1.56$ \\
\hline Nitrous oxide & 0.000001 & $\$ 0.00$ & 0.000499 & $\$ 0.01$ & 0.000544 & $\$ 0.01$ \\
\hline Nitric oxide & $\mathrm{N} / \mathrm{A}$ & $\mathrm{N} / \mathrm{A}$ & 0.00029 & $\$ 0.01$ & 0.00029 & $\$ 0.01$ \\
\hline Sulfur dioxide & 0.0004 & $\$ 0.01$ & 0.05 & $\$ 1.43$ & 0.10 & $\$ 2.62$ \\
\hline Sulfur oxides & 0.000003 & $\$ 0.00$ & 0.006 & $\$ 0.12$ & 0.007 & $\$ 0.14$ \\
\hline Particulates $\left(\mathrm{PM}_{10}\right)$ & 0.013 & $\$ 1.45$ & 0.0499 & $\$ 5.51$ & 0.0499 & $\$ 5.51$ \\
\hline VOC & 0.008 & $\$ 0.04$ & 0.014 & $\$ 0.06$ & 0.015 & $\$ 0.06$ \\
\hline Methane & 0.00002 & $\$ 0.00$ & 0.024 & $\$ 0.03$ & 0.998 & $\$ 1.07$ \\
\hline Acrolein & $\mathrm{N} / \mathrm{A}$ & $\mathrm{N} / \mathrm{A}$ & 0.00008618 & $\$ 0.02$ & 0.00008618 & $\$ 0.02$ \\
\hline Arsenic & $\mathrm{N} / \mathrm{A}$ & $\mathrm{N} / \mathrm{A}$ & 0.00000100 & $\$ 0.00$ & 0.00000150 & $\$ 0.00$ \\
\hline Cadmium & $\mathrm{N} / \mathrm{A}$ & $\mathrm{N} / \mathrm{A}$ & 0.00000020 & $\$ 0.00$ & 0.00000027 & $\$ 0.00$ \\
\hline Lead & $\mathrm{N} / \mathrm{A}$ & $\mathrm{N} / \mathrm{A}$ & 0.00000163 & $\$ 0.00$ & 0.00000213 & $\$ 0.00$ \\
\hline Mercury & 0.00000009 & $\$ 0.00$ & 0.00000020 & $\$ 0.00$ & 0.00000030 & $\$ 0.01$ \\
\hline Arsenic & 0.0000035 & $\$ 0.00$ & 0.0000043 & $\$ 0.00$ & 0.0068039 & $\$ 6.52$ \\
\hline Chromium & 0.000014 & $\$ 0.01$ & 0.000017 & $\$ 0.01$ & 0.006350 & $\$ 4.36$ \\
\hline Copper & 0.000008 & $\$ 0.00$ & 0.000010 & $\$ 0.00$ & 0.003175 & $\$ 0.00$ \\
\hline Zinc & $\mathrm{N} / \mathrm{A}$ & N/A & 0.00000024 & $\$ 0.00$ & 0.00000024 & $\$ 0.00$ \\
\hline Damage cost total: & & $\$ 1.55$ & & $\$ 7.16$ & & $\$ 21.38$ \\
\hline Product price: & & $\$ 25.38$ & & $\$ 25.38$ & & $\$ 25.38$ \\
\hline Full-cost price: & & $\$ 26.93$ & & $\$ 32.54$ & & $\$ 46.76$ \\
\hline
\end{tabular}

${ }^{*} \mathrm{~N} / \mathrm{A}=$ data not available

*damage costs are reported in year 2018 US dollars

Study assumptions for galvanized steel guardrail posts also follow Bolin and Smith's (2012) work. Steel is manufactured in a blast furnace from iron ore and 29\% recycled steel using a mix of domestic and international sources. The hot-dip galvanizing process applies 1.7 pounds of zinc per post. All steel posts are assumed to be recycled following removal from service.

Transportation distances associated with product distribution are assumed to be similar for both wood and steel alternatives.

Secondary emissions data for the two products were obtained from the NREL U.S. Life Cycle Inventory (USLCI) database (2012) and Bolin and Smith (2012). Individual emissions specific to the guardrail material, boundary condition, and data source were quantified and normalized to the functional unit. Emission outputs were then categorized 
as classical pollutants, greenhouse gases, or trace pollutants. Categorizing pollutants into one of these three categories allowed the study authors to determine variability around emission specific damage costs. Emissions were also identified as elementary flows into air, water, or soil, recognizing that emission damage costs change, dependent upon their transportation fate (Supplemental Materials Table 1).

Table 2. LCl of Emissions for One Galvanized Steel Highway Guardrail Post

\begin{tabular}{|c|c|c|c|c|c|c|}
\hline Data Source: & \multirow{2}{*}{\multicolumn{2}{|c|}{$\begin{array}{c}\text { NREL } 2012 \\
\text { Gate-to-qate }\end{array}$}} & \multicolumn{2}{|c|}{ Bolin et al. 2012} & \multicolumn{2}{|c|}{ Bolin et al. 2012} \\
\hline System Boundary: & & & Cradle- & -gate & Cradle-t & grave \\
\hline & $\begin{array}{l}\text { Emission } \\
(\mathrm{kg})\end{array}$ & $\begin{array}{c}\text { Damage } \\
\text { cost }\end{array}$ & $\begin{array}{c}\text { Emission } \\
(\mathrm{kg})\end{array}$ & $\begin{array}{c}\text { Damage } \\
\text { cost }\end{array}$ & $\begin{array}{l}\text { Emission } \\
(\mathrm{kg})\end{array}$ & $\begin{array}{c}\text { Damage } \\
\text { cost }\end{array}$ \\
\hline $\mathrm{CO}_{2}-$ fossil & 65.40 & $\$ 2.79$ & 53.98 & $\$ 2.30$ & 53.52 & $\$ 2.28$ \\
\hline $\mathrm{CO}_{2}-$ non fossil & 0.006 & $\$ 0.00$ & 0.005 & $\$ 0.00$ & 0.862 & $\$ 0.04$ \\
\hline Carbon monoxide & 0.610 & $\$ 0.03$ & 0.590 & $\$ 0.03$ & 0.050 & $\$ 0.00$ \\
\hline Ammonia & 0.000049 & $\$ 0.00$ & 0.000033 & $\$ 0.00$ & 0.000054 & $\$ 0.00$ \\
\hline Hydrochloric acid & 0.0008 & $\$ 0.00$ & 0.0005 & $\$ 0.00$ & 0.0100 & $\$ 0.03$ \\
\hline Hydrofluoric acid & 0.00011 & $\$ 0.00$ & 0.00007 & $\$ 0.00$ & 0.00127 & $\$ 0.01$ \\
\hline Nitrogen oxides & 0.09 & $\$ 1.68$ & 0.09 & $\$ 1.56$ & 0.06 & $\$ 1.15$ \\
\hline Nitrous oxide & $\mathrm{N} / \mathrm{A}$ & $\mathrm{N} / \mathrm{A}$ & 0.000020 & $\$ 0.00$ & 0.000100 & $\$ 0.00$ \\
\hline Nitric oxide & $\mathrm{N} / \mathrm{A}$ & $\mathrm{N} / \mathrm{A}$ & 0.00000 & $\$ 0.00$ & 0.00000 & $\$ 0.00$ \\
\hline Sulfur dioxide & 0.07 & $\$ 1.81$ & 0.05 & $\$ 1.19$ & 0.32 & $\$ 8.45$ \\
\hline Sulfur oxides & 0.140 & $\$ 2.63$ & 0.100 & $\$ 1.87$ & 0.012 & $\$ 0.22$ \\
\hline Particulates $\left(\mathrm{PM}_{10}\right)$ & 0.0158 & $\$ 1.74$ & 0.0022 & $\$ 0.25$ & 0.0034 & $\$ 0.37$ \\
\hline VOC & 0.005 & $\$ 0.02$ & 0.006 & $\$ 0.03$ & 0.005 & $\$ 0.02$ \\
\hline Methane & 0.037 & $\$ 0.04$ & 0.29 & $\$ 0.03$ & 0.109 & $\$ 0.12$ \\
\hline Acrolein & 0.00000016 & $\$ 0.00$ & 0.00000010 & $\$ 0.00$ & 0.00000240 & $\$ 0.00$ \\
\hline Arsenic & 0.00000057 & $\$ 0.00$ & 0.00000035 & $\$ 0.00$ & 0.00000354 & $\$ 0.00$ \\
\hline Cadmium & 0.00000014 & $\$ 0.00$ & 0.00000010 & $\$ 0.00$ & 0.00000054 & $\$ 0.00$ \\
\hline Lead & 0.00000056 & $\$ 0.00$ & 0.00000035 & $\$ 0.00$ & 0.00000367 & $\$ 0.00$ \\
\hline Mercury & 0.00000031 & $\$ 0.01$ & 0.00000019 & $\$ 0.00$ & 0.00000000 & $\$ 0.00$ \\
\hline Arsenic & $\mathrm{N} / \mathrm{A}$ & N/A & 0.0000000 & $\$ 0.00$ & 0.0000000 & $\$ 0.00$ \\
\hline Chromium & 0.000001 & $\$ 0.00$ & 0.000000 & $\$ 0.00$ & 0.000000 & $\$ 0.00$ \\
\hline Copper & $\mathrm{N} / \mathrm{A}$ & $\mathrm{N} / \mathrm{A}$ & 0.000000 & $\$ 0.00$ & 0.000000 & $\$ 0.00$ \\
\hline Zinc & $\mathrm{N} / \mathrm{A}$ & $\mathrm{N} / \mathrm{A}$ & 0.00149685 & $\$ 0.00$ & 0.09525432 & $\$ 0.26$ \\
\hline Damage cost total: & & $\$ 14.80$ & & $\$ 7.26$ & & $\$ 12.96$ \\
\hline Product price: & & $\$ 47.27$ & & $\$ 47.27$ & & $\$ 47.27$ \\
\hline Full-cost price: & & $\$ 62.07$ & & $\$ 54.53$ & & $\$ 60.23$ \\
\hline
\end{tabular}

${ }^{*} \mathrm{~N} / \mathrm{A}=$ data not available

*damage costs are reported in year 2018 US dollars

Relevant guardrail post emissions, identified by life-cycle inventories from the NREL U.S. Life Cycle Inventory (USLCI) database (2012) and Bolin and Smith (2012), were then assigned a damage cost according to Bruyn et al.'s (2010) emissions valuation. These previously determined damage costs place a direct monetary value on an individual emission that reflects its impact on human health, ecosystems, crops, and buildings (Supplemental Materials Table 2). For more suitable application in our study, the damage costs provided by Bruyn et al. (2010) were converted to year 2018 U.S. dollars using the Euro to US dollar exchange rate and consumer price index. They are reported in Table 3. By utilizing the damage costs reported by Bruyn et al. (2010) in our analysis, we inherently assume that the variables relating to emissions dispersion, concentration increases, doseresponse functions, and human health valuation are similar from Europe to the U.S. This 
is clearly not the case, but this assumption allows the use of a single set of internally consistent data, which was deemed to be critical for the initial development of the methodology and comparison of the processes. Emissions with a large source of uncertainty related to assigning the damage cost are identified within the table. However, these emissions were not significant enough to influence the interpretation of results.

Table 3. Emission Damage Costs (\$/kg, year 2018), Adapted from Bruyn et al. (2010)

\begin{tabular}{|c|c|c|c|}
\hline Emission: & Pollutant category: & Emitted to: & Emission price $(\$ / \mathrm{kg}):$ \\
\hline $\mathrm{CO}_{2}-$ fossil & Greenhouse gas & air & $\$ 0.04$ \\
\hline $\mathrm{CO}_{2}-$ non fossil & Greenhouse gas & Air & $\$ 0.04$ \\
\hline Carbon monoxide & Classical & Air & $\$ 0.05$ \\
\hline Ammonia & Classical & Air & $\$ 47.37$ \\
\hline Hydrochloric acid & Trace & Air & $\$ 2.81^{\mathrm{a}}$ \\
\hline Hydrofluoric acid & Trace & Air & $\$ 9.35$ \\
\hline Nitrogen oxides & Classical & Air & $\$ 18.06^{\mathrm{a}}$ \\
\hline Nitrous oxide & Greenhouse gas & Air & $\$ 12.69$ \\
\hline Nitric oxide & Classical & Air & $\$ 18.06$ \\
\hline Sulfur dioxide & Classical & Air & $\$ 26.24$ \\
\hline Sulfur oxides & Classical & Air & $\$ 18.74$ \\
\hline Particulates (PM 10$)$ & Classical & Air & $\$ 110.41$ \\
\hline VOC & Classical & Air & $\$ 4.33$ \\
\hline Methane & Greenhouse gas & Air & $\$ 1.07$ \\
\hline Acrolein & Trace & Air & $\$ 216.39$ \\
\hline Arsenic & Trace & Air & $\$ 1,381.82$ \\
\hline Cadmium & Trace & Air & $\$ 216.39$ \\
\hline Lead & Trace & Water & $\$ 14.36$ \\
\hline Mercury & Trace & Air & $\$ 18,742.37$ \\
\hline Arsenic & Trace & Water & $\$ 957.56$ \\
\hline Chromium & Trace & Water & $\$ 686.65$ \\
\hline Copper & Trace & Water & $\$ 0.01^{\mathrm{a}}$ \\
\hline Zinc & Trace & Water & $\$ 2.74$ \\
\hline
\end{tabular}

a indicates source of uncertainty

The average market price for a galvanized steel guardrail post was obtained by averaging market prices from six building product distributors around the U.S. and ranged from $\$ 36.00$ to $\$ 65.00$. The price for CCA-treated wood was obtained by averaging market prices from ten online retail businesses and ranged from $\$ 20.11$ to $\$ 36.00$. Full-cost prices for treated wood and galvanized steel guardrail posts were derived by adding the product's market price to the sum of all relevant damage costs (Eq. 1). For the purpose of this study, all emission damage costs were converted to U.S. dollars based on the 2008 euro to U.S. dollar exchange rate and were inflated to year 2018 using the consumer price index.

$$
\text { Full-cost price }=\text { market price for post }+\sum(\text { emission damage costs })
$$

$$
\text { Standard deviation }=\sqrt{\frac{\sum(x-\bar{x})^{2}}{(n-1)}}
$$

At the onset of this research, it was necessary to determine whether it was appropriate to use emission damage cost or emission abatement costs to generate full-cost prices for CCA-treated wood and galvanized steel guardrail posts. Bruyn et al. (2010) 
provides a helpful rule to assist with that decision, i.e. "if a project leads to changes in environmental quality, damage costs should be used; if it leads to changes in efforts to secure environmental targets, abatement costs should be used." This study ultimately addresses product substitution between treated wood and galvanized steel guardrail posts that, if implemented, will result in overall changes to air, water, and soil quality. Therefore, the most appropriate way to determine full-cost prices for this study was to utilize emission damage costs.

To estimate variability around full-cost prices and emission damage costs, Monte Carlo simulations via Crystal Ball software were performed. As required by Monte Carlo simulation, product price and emission damage cost variability and distribution shape were defined according to secondary studies. Market prices for guardrail posts were assumed to have a normal distribution with a standard deviation defined by Equation 2. As reported by Bruyn et al. (2010), classical emission damage costs followed a log-normal distribution with a standard deviation equivalent to the emission central value divided by 3 . Trace emission damage costs followed a log-normal distribution with a standard deviation equivalent to the emission central value divided by 4 . The log-normal distributions used to describe classical and trace emission damage costs in this study appear frequently in the natural sciences and are used to describe datasets derived from multiplicative independent variables where values cannot be negative and variances are large. Along with emission damage costs, other interesting applications of the log-normal distribution are species abundance, women's height, and even the distribution of minerals in the Earth's crust (Limpert et al. 2001).

Regarding the damage cost variability of greenhouse gases, Tol (2005) analyzed over one-hundred previously published carbon dioxide damage cost estimates and generated a composite probability density function. Tol's (2005) findings, utilized for this study, found that greenhouse gas emission prices followed a strongly right-skewed distribution with a median of $\$ 6.47 /$ tonne of $\mathrm{CO}_{2}$, a mean of $\$ 43.28 /$ tonne of $\mathrm{CO}_{2}$, and a $95 \%$ right-tail value of $\$ 161.87 /$ tonne of $\mathrm{CO}_{2}$.

After defining pollutant distributions, Monte Carlo simulation was used to create full-cost and damage-cost distributions for wood and steel guardrail posts based on 10,000 randomly generated point estimates. Simulation results defined $95 \%$ confidence intervals around full-cost price estimates and $90 \%$ confidence intervals around individual emission damage costs. Results helped determine which product emissions were the major drivers for overall prices and highlighted how damage costs might fluctuate based on the assumed distribution. Sensitivity analysis results for emission damage costs, derived from Monte Carlo simulations, are provided in Figs. 2 through 5. Lower and upper bound data labels indicate individual emission damage costs at $10 \%$ and $90 \%$ confidence limits and correspond to the total emission damage cost represented on the horizontal axis, given that all other variables are held constant.

\section{RESULTS AND DISCUSSION}

The cost of a guardrail post, whether made of treated wood or galvanized steel, varies considerably based on market conditions. Because posts are typically sold as components in a construction project through specialty construction wholesalers and retailers, post prices can be influenced by a number of factors including order size, material availability, transportation distance, and local product demand. The market prices obtained 
for this work suggested that treated wood guardrail posts cost less per unit than galvanized steel alternatives. The average cost of a six-foot long CCA-treated wood post used for this study was $\$ 25.38 \pm \$ 4.60$. The price of a galvanized steel post was $\$ 47.27 \pm \$ 10.48$. These prices are similar to Smith's (2013), which reported treated wood and galvanized steel guardrail costs of $\$ 31.50$ and $\$ 56.10$ per six feet, respectively.

After assessing market prices for the two products, damage costs were added to those market prices based on findings from secondary emission valuation and life-cycle analysis studies. By combining these two elements, we generated full-cost prices for CCAtreated wood and galvanized steel guardrail posts based on multiple product system boundary conditions. Full-cost prices by product and boundary condition are presented in Fig. 1. Based on our full-cost price methodology, even after considering product externalities, CCA-treated wood guardrail posts proved to be the economical alternative to galvanized steel posts. Intuitively, as product system boundary conditions were expanded to include the end-of-life product disposal or recycling stage, full-cost prices increased. It is important to note that damage costs reported in these findings are likely conservative in nature. Because dry and lined landfills either inhibit wood decay or capture preservative leachates, in practical applications, it is likely that outputs such as methane, chromium, and arsenic are prevented from being released into the environment. Please consider the conservative nature of preservative treated wood damage costs when interpreting results. To get a better understanding of which emissions drive overall damage costs, we turned to sensitivity analysis.

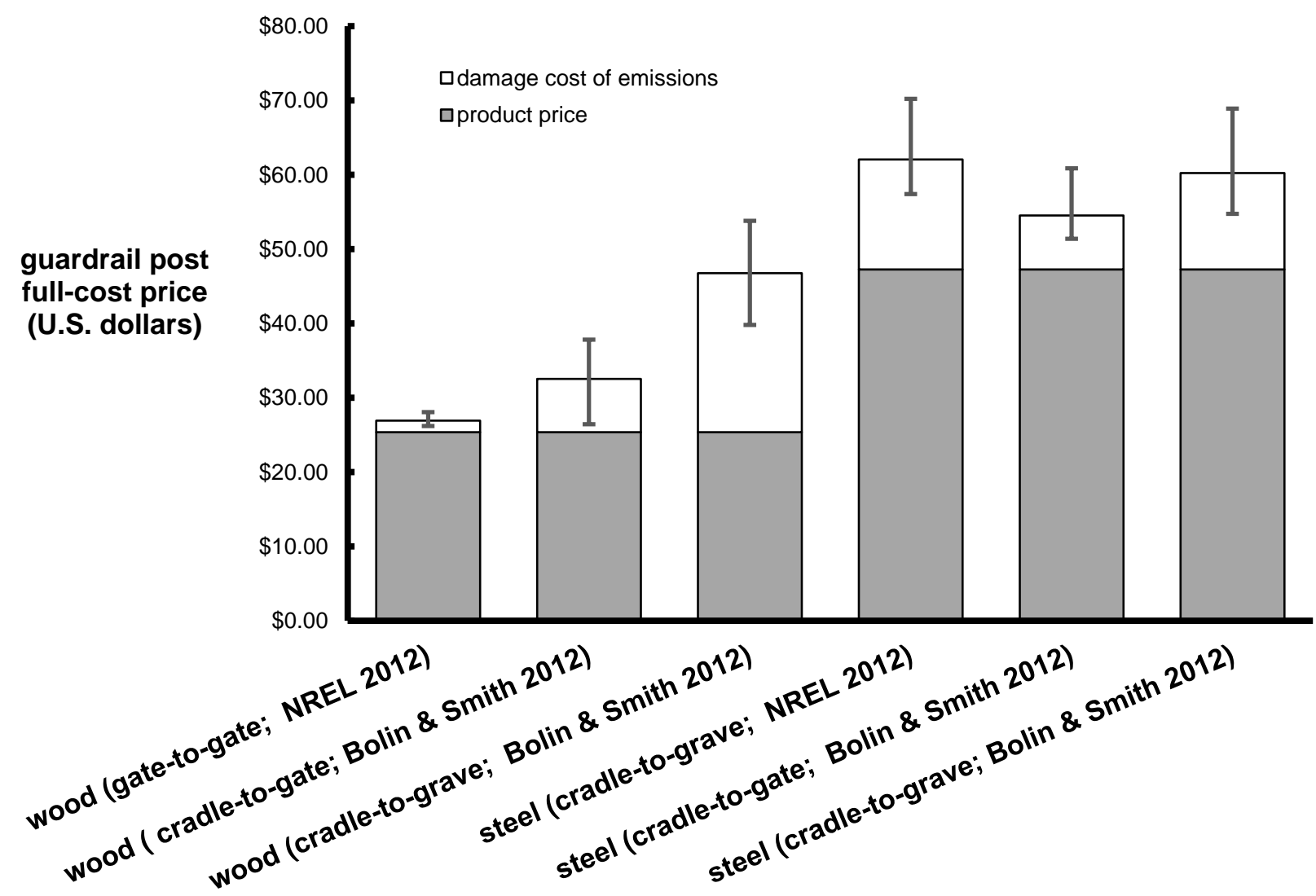

Fig. 1. Full-cost price comparison for highway guardrail post alternatives (error bars indicate damage cost $95 \%$ confidence limits) 
Full-cost price estimates for CCA-treated guardrail posts varied significantly based on the system boundary conditions used to quantify emissions. NREL data from the USLCI database for "post, softwood, CCA, treated, southeast" represented a gate-to-gate unit process that likely did not include backward-linked processes such as forest harvesting or transportation, or forward-linked stages such as product use or disposal. The full-cost price for a CCA-treated guardrail post in this scenario, provided in Table 1, was \$26.93 (95\% CI: \$17.86, \$36.17; Supplemental Materials Fig. 1). Emission damage costs, which followed a lognormal distribution, amounted to \$1.55 (95\% CI: \$0.82, \$2.69; Supplemental Materials Fig. 2) and represented approximately $6 \%$ of the post's full-cost price. Damage costs were primarily driven by $\mathrm{PM}_{10}$ generated during production of the CCA preservative and amounted to $\$ 1.45$. Volatile organic compounds (VOC) resulting from lumber drying (NREL 2012) were also present, but only contributed \$0.04. These two emissions accounted for $96 \%$ of the total damage costs and explained $99.85 \%$ of damage cost variation. Carbon dioxide, arsenic, and chromium emissions detailed in this data source were present, but not in large enough quantities to be considered economically significant. Insignificant heavy metal emissions presented in this scenario were likely a result of the system boundary conditions that appeared to exclude end-of-life.

Bolin and Smith (2012) provided cradle-to-gate emission data for CCA-treated guardrail posts that included backward-linked product stages including raw material extraction, primary and secondary manufacturing, and transportation within the system boundary. As a result, the full-cost price for treated guardrail posts (Table 1) in this scenario rose from \$26.93 to \$32.54 (95\% CI: \$20.94, \$42.51; Supplemental Materials Fig. 3). Emission damage costs amounted to $\$ 7.16$ (95\% CI: \$1.06, \$12.44; Supplemental Materials Fig. 4). Significant emission cost drivers in this scenario were $\mathrm{PM}_{10}$, anthropogenic $\mathrm{CO}_{2}, \mathrm{SO}_{x}$, and $\mathrm{NO}_{\mathrm{x}}$ (Fig. 2).

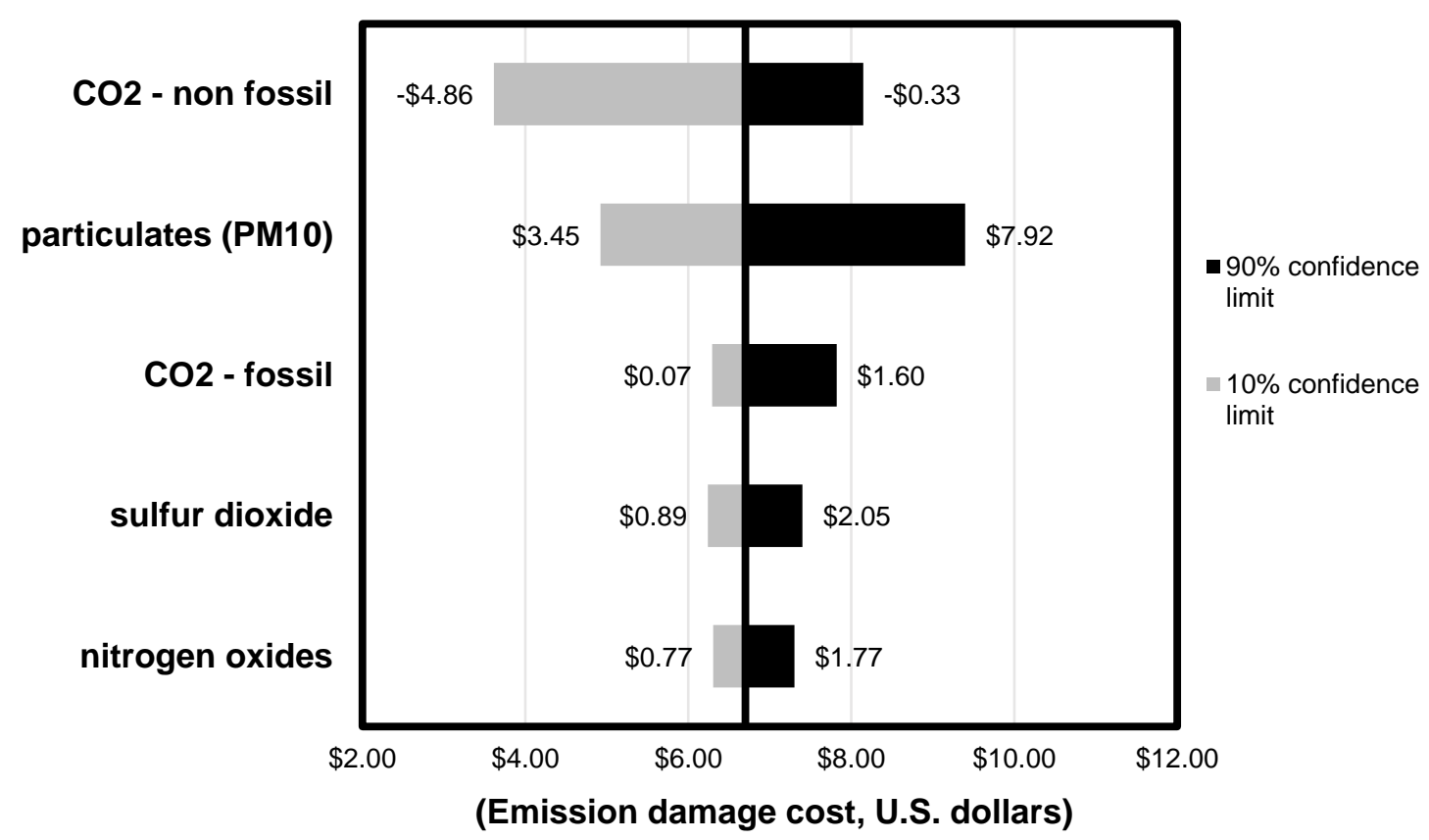

Fig. 2. Sensitivity analysis of significant emissions associated with CCA-treated wooden guardrail posts (cradle-to-gate scenario). Total full-cost price was $\$ 32.54$. 
These emissions explained approximately 55\% of damage cost variability. Biogenic carbon is also a significant contributor to damage costs but acted as a carbon sequestration credit. By choosing to differentiate between biogenic and anthropogenic $\mathrm{CO}_{2}$ emissions, wooden posts sequestered carbon and reduced $\mathrm{CO}_{2}$ emissions by 30 kilograms per post. By factoring in the role of carbon sequestration, damage costs were reduced by $\$ 1.97$ in this scenario.

Lastly, when the wooden guardrail post system was analyzed based on cradle-tograve boundary conditions, which included product use and disposal into the system boundary, additional $\mathrm{CO}_{2}, \mathrm{NO}_{x}, \mathrm{SO}_{x}$, methane, and trace pollutant emissions were generated. Under this scenario, the full-cost price for a treated guardrail reported in Table 1 rose to $\$ 46.76$ (95\% CI: $\$ 35.29, \$ 58.13$; Supplemental Materials Fig. 5). Arsenic and chromium were economically significant emissions that appeared in this scenario as they leach during use and landfilling stages (Fig. 3).

These trace pollutants contributed $\$ 10.88$ worth of damage costs to the full-cost price. Methane release during landfilling also caused the full-cost price to rise by $\$ 1.04$. Damage costs relating to anthropogenic carbon dioxide rose $\$ 0.30$, while the credit for biogenic carbon droped from $\$ 1.97$ to $\$ 1.51$. Because of these emissions and others, the total damage cost for CCA-treated guardrail posts was $\$ 21.38$ (95\% CI: $\$ 14.42,28.43$; Supplemental Materials Fig. 6). Based on study results, CCA-treated guardrail posts are a less expensive option based on their market price despite generating economically substantial externalities.

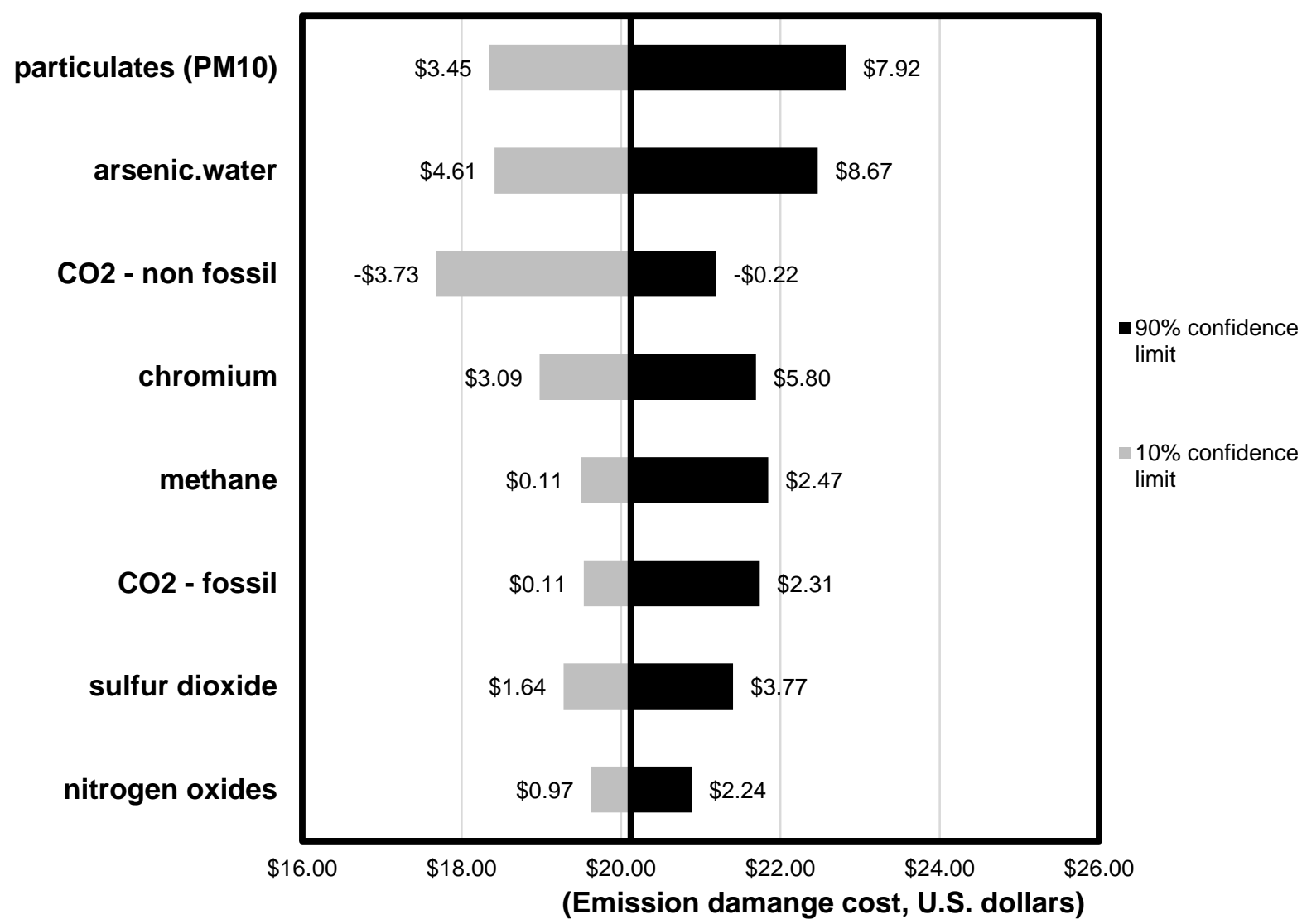

Fig. 3. Sensitivity analysis of significant emissions associated with CCA-treated wooden guardrail posts (cradle-to-grave scenario). Total full-cost price was $\$ 46.76$. 
As is the case with treated wood guardrail posts, steel posts also generated emissions that influenced the product's full-cost price. The average market price for a galvanized steel post was $\$ 47.27$ (Table 2). Utilizing NREL's (2012) life-cycle inventory database to quantify emissions, which reports gate-to-gate outputs, the full-cost price for a galvanized steel guardrail post was \$62.07 (95\% CI: \$40.94, \$83.42; Supplemental Materials Fig. 7). Damage costs associated with galvanized steel were $\$ 14.80$ (95\% CI: \$10.14, \$22.95; Supplemental Materials Fig. 8). Economically significant emissions related to this product were anthropogenic $\mathrm{CO}_{2}, \mathrm{SO}_{x}, \mathrm{PM}_{10}$, and $\mathrm{NO}_{\mathrm{x}}$. These emissions correspond with results reported by Tongpool et al. (2010), who found that the energyintensive galvanized steel manufacturing system generated substantial global warming potential (GWP) and particulate matter as a result of primary slab steel production and the coal-generated electricity required for manufacturing. Their research also highlighted the significant role zinc played in increasing GWP, carcinogens, and respiratory inorganics. They assert that when cold-rolled steel goes through the hot-dipped galvanizing process, additional fossil fuel and mineral consumption triples the product's total GWP and quadruples respiratory impacts. Note that this finding is contradictory to the American Galvanizers Association (2018), which asserts that the recycling rates of steel and zinc, $70 \%$ and $30 \%$ respectively, are large enough to make steel a more environmentally friendly material than wood and that the galvanization process does not make a difference in the environmental impact.

Bolin and Smith's (2012) life-cycle analysis confirm the aforementioned emissions reported by Tongpool et al. (2010). By utilizing their cradle-to-gate assessment in our emission valuation, $\mathrm{CO}_{2}, \mathrm{SO}_{\mathrm{x}}$, and $\mathrm{NO}_{\mathrm{x}}$ were determined to be the main contributors to galvanized steel damage costs (Fig. 4).

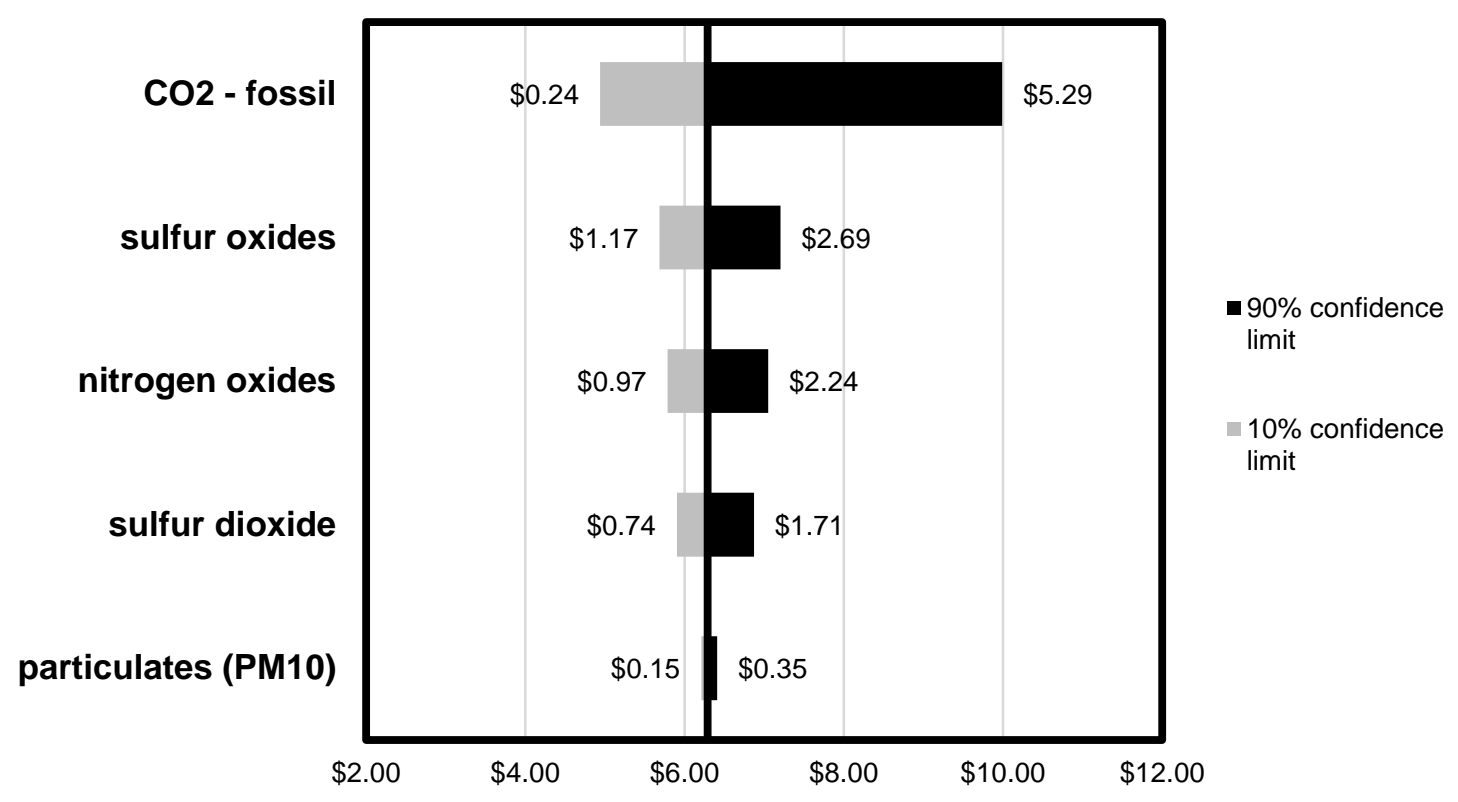

(Emission damage cost, U.S. dollars)

Fig. 4. Sensitivity analysis of significant emissions associated with galvanized steel guardrail posts (cradle-to-gate scenario). Total full-cost price was $\$ 54.53$. 
The full-cost price of a galvanized steel guardrail post (Table 2) in this context was \$54.53 (95\% CI: \$33.44, \$75.76; Supplemental Materials Fig. 9). Approximately 13\% of this price, or $\$ 7.16$ (95\% CI: \$4.12, \$13.60; Supplemental Materials Fig. 10) represented emission damage costs. The main source of emissions price variability is anthropogenic $\mathrm{CO}_{2}$, which explained $84 \%$ of damage cost variation. It is also interesting to note that $\mathrm{PM}_{10}$ emissions that were significant in NREL's (2012) emission inventory, were significantly smaller in Bolin and Smith's (2012) study, and added only \$0.25 to the total damage cost as opposed to $\$ 1.74$. Cradle-to-gate emission damage costs for treated wood and galvanized steel were similar based on LCI results, being $\$ 7.16$ and $\$ 7.26$, respectively.

Finally, the full-cost price for a galvanized steel post (Table 2) based on Bolin and Smith's (2012) cradle-to-grave assessment was \$60.23 (95\% CI: \$38.49, \$82.49; Supplementary Materials Fig. 11). When use and end-of-life were considered a sevenfold increase in $\mathrm{SO}_{\mathrm{x}}$ emissions was observed, which contributed significantly to the damage cost estimate of $\$ 12.96$ (95\% CI: \$7.48, \$21.64; Supplementary Materials Fig. 12). Damage costs from $\mathrm{SO}_{\mathrm{x}}$ climbed from $\$ 1.19$ in the cradle-to-gate scenario to $\$ 8.45$ in the cradle-to-grave scenario. This increase is attributed to the recycling assumptions used in their study, particularly the additional energy inputs required for the electric arc furnace. Anthropogenic $\mathrm{CO}_{2}$ and $\mathrm{NO}_{\mathrm{x}}$, generated by fossil fuel combustion and metal ore extraction, were also significant damage cost contributors in this scenario (Fig. 5).

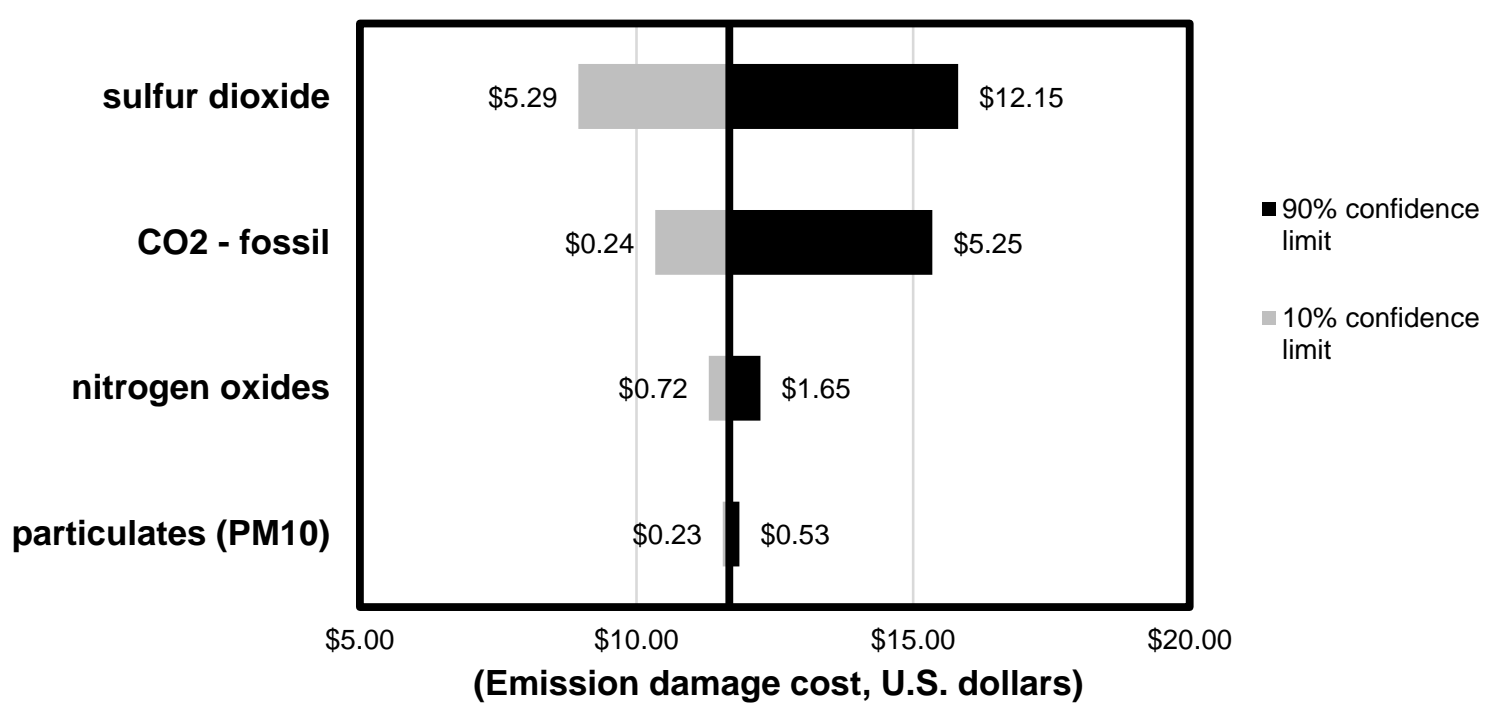

Fig. 5. Sensitivity analysis of significant emissions associated with galvanized steel guardrail posts (cradle-to-grave scenario). Total full-cost price was $\$ 60.23$.

\section{Study Limitations}

Market prices for treated wood and galvanized steel guardrail posts are difficult to estimate because they are not end-use consumer products that are sold with defined prices. Instead, construction contractors work with product distributors to negotiate an acceptable price based on order size, shipping rates, product availability, and order urgency. The high product price variability observed in this study is a result of the market influences mentioned above coupled alongside small estimate sample sizes $(\mathrm{n}<10)$. Since product prices varied significantly, the influence of market price tended to wash out the influence of emission damage costs when reporting full-cost prices. In our Monte Carlo simulations, 
product price variability explained anywhere from $66 \%$ to $99 \%$ of full-cost price variability depending on the scenario. This observation should not suggest that emission damage costs do not play a significant enough role in full-cost price estimation to warrant studying. Instead, these results should be interpreted by holding market prices constant while examining damage cost variability based on regional variables.

Utilizing emission valuations from Bruyn et al. (2010) for this work carries along uncertainty inherent within the IPA methodology. Five individual sources of uncertainty have been identified with this method; uncertainty related to data, uncertainty related to modeling, uncertainty related to political and ethical choices, uncertainty about future conditions, and idiosyncrasies of the analyst (ExternE 2014). In addition to these uncertainties, this study takes the liberty of using European value judgements and externality valuations and applies them to a scenario taking place in the U.S. For example, Bruyn et al. (2010) defines the value of a year of life lost at $\$ 68,154$ and the value of a lost day of work at $\$ 503$ (adjusted from year 2008 Euros to year 2018 U.S. dollars). These figures were derived based on economic conditions specific to the European Union as well as survey results which described European residents' "willingness to pay" for mortality risk reduction. Therefore, emission damage costs derived from these values may or may not adequately reflect the damage costs associated with U.S emissions.

In addition to health-related impacts, Europeans and Americans may also value biodiversity differently. In their work, Bruyn et al. (2010) define an emission's impact on biodiversity loss using potentially disappeared fraction of species (PDF). Also derived using "willingness to pay" studies, the European value for biodiversity loss is $\$ 0.77$ per PDF per square meter. This value may also be inherently different from European to American citizens, and that difference will be reflected within the ecosystem component of an emission's damage cost. Therefore, interpretation of these study results should consider that cultural norms around "willingness to pay" for human health and biodiversity, along with other demographic and geographic factors that influence emission damage costs like population density, income per capita, and weather patterns, were based on European data. However, because these inherent valuations are similar across both products in this study, it is reasonable to suggest that although emission damage costs may not be accurate in a U.S. geographical context, they still are useful for comparing product alternatives.

Future research comparing CCA-treated wood and galvanized steel guardrail post full-cost prices should focus on evaluating the role product service life plays in influencing full-cost price variability. For the present study, both alternatives were assumed to have similar 40-year service lives. However, it is likely that a percentage of wooden and steel posts would need to be removed from service early due to premature failure. It is also likely that a number of wooden posts could be reused following accidents that necessitate guardrail repair (Smith 2013). The present research could be enhanced by incorporating the cost of guardrail maintenance and post reuse into full-cost prices.

The goal of the full-cost accounting methodology is to incorporate financial, environmental, and social issues into the decision-making process. The results reported in this study have addressed financial and environmental product valuation well, but this study could be significantly improved by incorporating additional social impacts beyond the product's effect on human health. Factors worth considering are the wages and taxes generated by guardrail post manufacturing and its supporting supply chain, induced job creation, and workplace incidents in wood product manufacturing, steel manufacturing, and mining industries. Also, the increased aesthetic value of wooden $v s$. steel assemblies is not addressed herein. All of these categories could be quantified, valued, and normalized 
to the study's functional unit to generate a more comprehensive set of cradle-to-grave fullcost prices.

\section{CONCLUSIONS}

1. As noted above, environmental damage costs of chromated copper arsenate (CCA) posts are likely overstated due to assumptions that treated wood decays in landfills and that all constituents are released to groundwater. Even with this overestimate, CCA wood posts have less full cost than galvanized metal. If more realistic end-of-life assumptions were included, CCA wood damage costs would be reduced even further.

2. Emission damage costs varied significantly based on life-cycle inventory boundary conditions.

3. For both product alternatives, damage costs were significantly impacted by end-of-life assumptions.

4. For treated wood posts, $\mathrm{PM}_{10}$ generated during product manufacturing was the significant contributor to the damage cost while arsenic and chromium leaching in situ and during landfilling were major drivers for the damage cost during the product's endof-life.

5. For galvanized steel posts, damage costs were influenced by the specific process used for recycling.

6. Results from this study indicate that future efforts to reduce the full-cost price of a guardrail post should be focused on reducing emissions generated by arsenic and zinc manufacturing which create respiratory impacts for human health and contribute to global climate change.

7. The results support Kahn et al.'s (2006) conclusion that future efforts should be focused on reducing CCA leaching during treated wood use and end-of-life stages to prevent soil and groundwater contamination.

\section{REFERENCES CITED}

American Galvanizer's Association (2018). "HDG environmental advantages," (https://galvanizeit.org/hot-dip-galvanizing/is-galvanizing-sustainable/hdgenvironmental-advantages/\#infinitelyrenewable/), accessed: 11 June 2018.

Bailey, D. S. (2003). The Feasibility of Recycling CCA Treated Wood from Spent Residential Decks, Master's Thesis, Virginia Polytechnic Institute and State University, Blacksburg, VA, USA.

Bellver-Domingo, A., Fuentes, R., and Hernandez-Sancho, F. (2017). "Shadow prices of emerging pollutants in wastewater treatment plants: Quantification of environmental externalities," J. Environ. Manage. 203(1), 439-447. DOI: 10.1016/j.jenvman. 2017.08.025

Bickel, P., and Friedrich, R. (2005). ExternE Externalities of Energy: Methodology 2005 Update (EUR 21951), IER Institute for Energy Economics and Rational Use of Energy, University of Stuttgart, Germany. 
Bolin, C. A., and Smith, S. T. (2012). "Life cycle assessment of CCA-treated wood highway guard rail posts in the US with comparisons to galvanized steel guard rail posts," Journal of Transportation Technologies 3(1), 58-67. DOI: $10.4236 /$ jtts.2013.31007

Broadbent, C. (2012). LCI Data for Steel Products, World Steel Association, Belgium, (https://www.worldsteel.org/steel-by-topic/life-cycle-thinking/lca-lciform.html).

Bruyn, S., Korteland, M., Markowska, A., Davidson, M., Jong, F., Bles, M., and Sevenster, M. (2010). Shadow Prices Handbook: Valuation and Weighting of Emissions and Environ. Impacts (Tech. Rep. CE-10-7788-25), CE Delft, Netherlands.

Ellerman, A. D., Joskow, P. L., and Harrison, D. (2003). Emissions Trading in the US: Experiences, Lessons, and Considerations for Greenhouse Gases, Center for Climate and Energy Solutions, Arlington, Virginia.

Environmental Protection Agency (2016a). "Chromated arsenicals (CCA)," (https://www.epa.gov/ingredients-used-pesticide-products/chromated-arsenicals-cca), accessed 14 August 2020.

Environmental Protection Agency (2016b). "Nitrogen dioxide $\left(\mathrm{NO}_{2}\right)$ pollution," (https://www.epa.gov/no2-pollution), accessed 14 August 2020.

Environmental Protection Agency. (2016c). "Sulfur dioxide $\left(\mathrm{SO}_{2}\right)$ pollution," (https://www.epa.gov/so2-pollution), accessed 14 August 2020.

ExternE. (2014). "External costs of energy: Uncertainties," (http://www.externe.info/externe_d7/?q=node/54/), accessed 15 May 2018.

Hingston, J. A., Collins, C. D., Murphy, R. J., and Lester, J. N. (2001). "Leaching of chromated copper arsenate wood preservatives: A review," Environ. Pollut 111(1), 53-66. DOI: 10.1016/S0269-7491(00)00030-0

Jasinski, D., Merdith, J., and Kirwan, K. (2015). "A comprehensive review of full cost accounting methods and their applicability to the automotive industry," J. Clean. Prod. 108(A), 1123-1139. DOI: 10.1016/j.jclepro.2015.06.040

Jones, A. S., Marini, J., Solo-Gabriele, H. M., Robey, N. M., and Townsend, T. G. (2019). "Arsenic, copper, and chromium from treated wood products in the U.S. disposal sector," Waste Manage. 87, 731-740. DOI: 10.1016/j.wasman.2019.03.004

Krietemeyer, S., Tillman, J., Wahl, G., and Whitford, K. (1997). Treatment Technology Performance and Cost Data for Remediation of Wood Preserving Sites (EPA/625/R97/009), U.S. Environmental Protection Agency, Washington, DC.

Lebow, S. T. (2010). “Chapter 15 - Wood preservation," in: Wood Handbook - Wood as an Engineering Material, General Technical Report FPL-GTR-190, Department of Agriculture, Forest Service, Forest Products Laboratory, Madison, WI. DOI: 10.2737/FPL-GTR-190

Mercer, T. G., and Frostick, L. E. (2014). "Evaluating the potential for environmental pollution from chromated copper arsenate (CCA)-treated wood waste: A new mass balance approach," J. Hazard. Mater. 276, 10-18. DOI: 10.1016/j.jhazmat.2014. 05.006

Miner, R. (2010). Impact of the Global Forest Industry on Atmospheric Greenhouse Gases (FAO Forestry Paper 159), Food and Agricultural Organization of the United Nations, Rome, Italy.

Morrell, J. J. (2018). "Protection of wood based materials," in: Handbook of Environmental Degradation of Materials, M. Kutz (ed.), William Andrew, New York, NY. DOI: 10.1016/B978-0-323-52472-8.00017-4

National Renewable Energy Laboratory (2012). "Federal LCA commons," 
(https://www.lcacommons.gov/lca-collaboration/search), accessed 14 August 2020.

Nguyen, T. L. T., Laratte, B., Guillaume, B., and Hua, A. (2016). "Quantifying environmental externalities with a view to internalizing them in the price of products, using different monetization models," Resour. Conserv. Recy. 109, 13-23. DOI: 10.1016/j.resconrec.2016.01.018

Ohgami, N., Yamanoshita, O., Dinh Than, N., Yajima, I., Nakano, C., Wenting, W., Ohnuma, S., and Kato, M. (2015). "Carcinogenic risk of chromium, copper, and arsenic in CCA-treated wood," Environ. Pollut. 206, 456-460. DOI: 10.1016/j.envpol.2015.07.041

Radics, R. I., Dasmohapatra, S., and Kelley, S. S. (2016). "Use of linear programming to optimize the social, environmental, and economic impacts of using woody feedstocks for pellet and torrefied pellet production," Biofuel Bioprod. Bior. 10(4), 446-461. DOI: $10.1002 / \mathrm{bbb} .1658$

Shaik, S., Helmers, G. A., and Langemeier, M. R. (2002). "Direct and indirect shadow price and cost estimates of nitrogen pollution abatement," J. Agr. Resour. Econ. 27(2), 420-432.

Smith, S. T. (2013). Economic Evaluation of Treated Wood and Galvanized Steel Guardrail Posts, Western Wood Preservers Institute, Vancouver, WA, (https://preservedwood.org/portals/0/documents/EconEval_Guardrail.pdf), accessed 14 August 2020.

Smith, S. T. (2020). "Water-borne wood preservation and end-of-life removal history and projection," Engineering 12, 117-139.

Tol, R. S. J. (2018). "The economic impacts of climate change," Rev. Env. Econ. Policy 12(1), 4-25. DOI: 10.1093/reep/rex027

Tongpool, R., Jirajariyavech, A., Yuvaniyama, C., and Mungcharoen, T. (2010). "Analysis of steel production in Thailand: environmental impacts and solutions," Energy 35(10), 4192-4200. DOI: 10.1016/j.energy.2010.07.003

Townsend, T., Solo-Gabriele, H., Yolaymat, T., Stook, K., and Hosein, N. (2003). "Chromium, copper, and arsenic concentrations in soil underneath CCA-treated wood structures," Soil Sediment Contam. 12(6), 779-798. DOI: 10.1080/1058833039025 4829

Townsend, T., Tolaymat, T., Solo-Gabriele, H., Dubey, B., Stook, K., and Wadanambi, L. (2004). "Leaching of CCA-treated wood: Implications for waste disposal," $J$. Hazard. Mater. 114(1-3), 75-91. DOI: 10.1016/j.jhazmat.2004.06.025

Townsend, T., Dubey, B., Tolaymat, T., and Solo-Gabriele, H. (2005). "Preservative leaching from weathered CCA-treated wood," J. Environ. Manage. 75(2), 105-113. DOI: $10.1016 /$ j.jenvman.2004.11.009

U.S. Department of Transportation (2015). "Crashes by first harmful event, Type of collision and crash severity, 2015," National Highway Traffic Safety Administration, (https://www.iii.org/table-archive/21904), accessed 14 August 2018.

Yuntzu-Yen Chen, A., and Olsen, T. (2016). "Chromated copper arsenate-treated wood: A potential source of arsenic exposure and toxicity in dermatology," International Journal of Women's Dermatology 2(1), 28-30. DOI: 10.1016/j.ijwd.2016.01.002

Article submitted: August 14, 2020; Peer review completed: September 27, 2020;

Revised version received: October 5, 2020; Accepted: October 6, 2020;

Published: October 16, 2020.

DOI: 10.15376/biores.15.4.9103-9127 


\section{APPENDIX}

\section{Supplemental Materials}

Table S1. Difference in Emission Damage Cost According to the Pollutant's Fate (adapted from Bruyn et al. 2010, reported in 2018 U.S. dollars per kg)

Emission damage cost $(\$ / \mathrm{kg})$ when emitted to:

\begin{tabular}{lrrr}
\hline Emission: & Air & Soil & Water \\
\hline Arsenic & $\$ 1381.82$ & $\$ 19.76$ & $\$ 957.56$ \\
Carbon dioxide & $\$ 0.04$ & $\mathrm{NA}$ & $\mathrm{NA}$ \\
Chromium VI & $\$ 284.54$ & $\$ 0.01$ & NA \\
Methane & $\$ 1.08$ & $\mathrm{NA}$ & $\mathrm{NA}$ \\
Nitrogen oxides & $\$ 18.06$ & $\mathrm{NA}$ & $\mathrm{NA}$ \\
Particulates & $\$ 110.41$ & $\mathrm{NA}$ & $\mathrm{NA}$ \\
Sulfur dioxide & $\$ 26.24$ & & $\mathrm{NA}$ \\
\hline
\end{tabular}

Table S2. Emission Damage Cost Breakdown According to the Emission's Impact on Human Health, Ecosystems, Crops, and Buildings (adapted from Bruyn et al. 2010, reported in 2018 U.S. dollars)

\begin{tabular}{|c|c|c|c|c|}
\hline \multicolumn{5}{|c|}{ Emission impact on: } \\
\hline Emission & Human Health & Ecosystems & $\begin{array}{c}\text { Crops and } \\
\text { Buildings }\end{array}$ & Total \\
\hline Arsenic & $\$ 1381.82$ & NA & NA & $\$ 1381.82$ \\
\hline Carbon dioxide & $\$ 0.01$ & $\$ 0.03$ & NA & $\$ 0.04$ \\
\hline Chromium VI & $N A^{*}$ & $N A^{*}$ & $N A^{*}$ & $N A^{*}$ \\
\hline Methane & 0.22 & 0.86 & NA & $\$ 1.08$ \\
\hline Nitrogen oxides & $\$ 15.80$ & $\$ 2.53$ & $\$-0.27$ & $\$ 18.06$ \\
\hline Particulates & $\$ 110.41$ & NA & NA & $\$ 110.41$ \\
\hline Sulfur dioxide & $\$ 24.72$ & $\$ 0.78$ & $\$ 0.74$ & $\$ 26.24$ \\
\hline
\end{tabular}




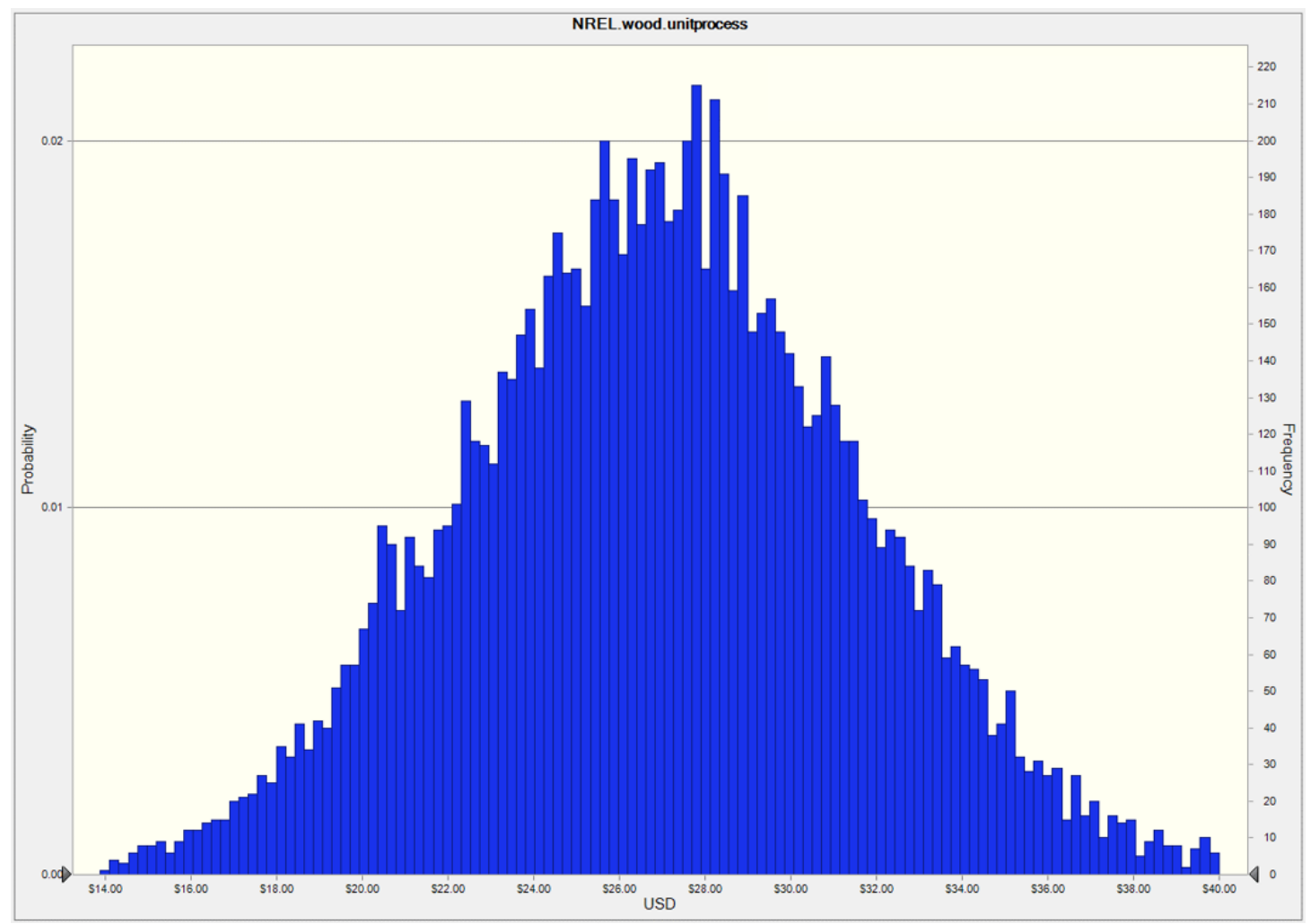

Fig. S1. CCA treated wood highway guardrail post full-cost price distribution (source: NREL 2012; boundary condition: unit process)

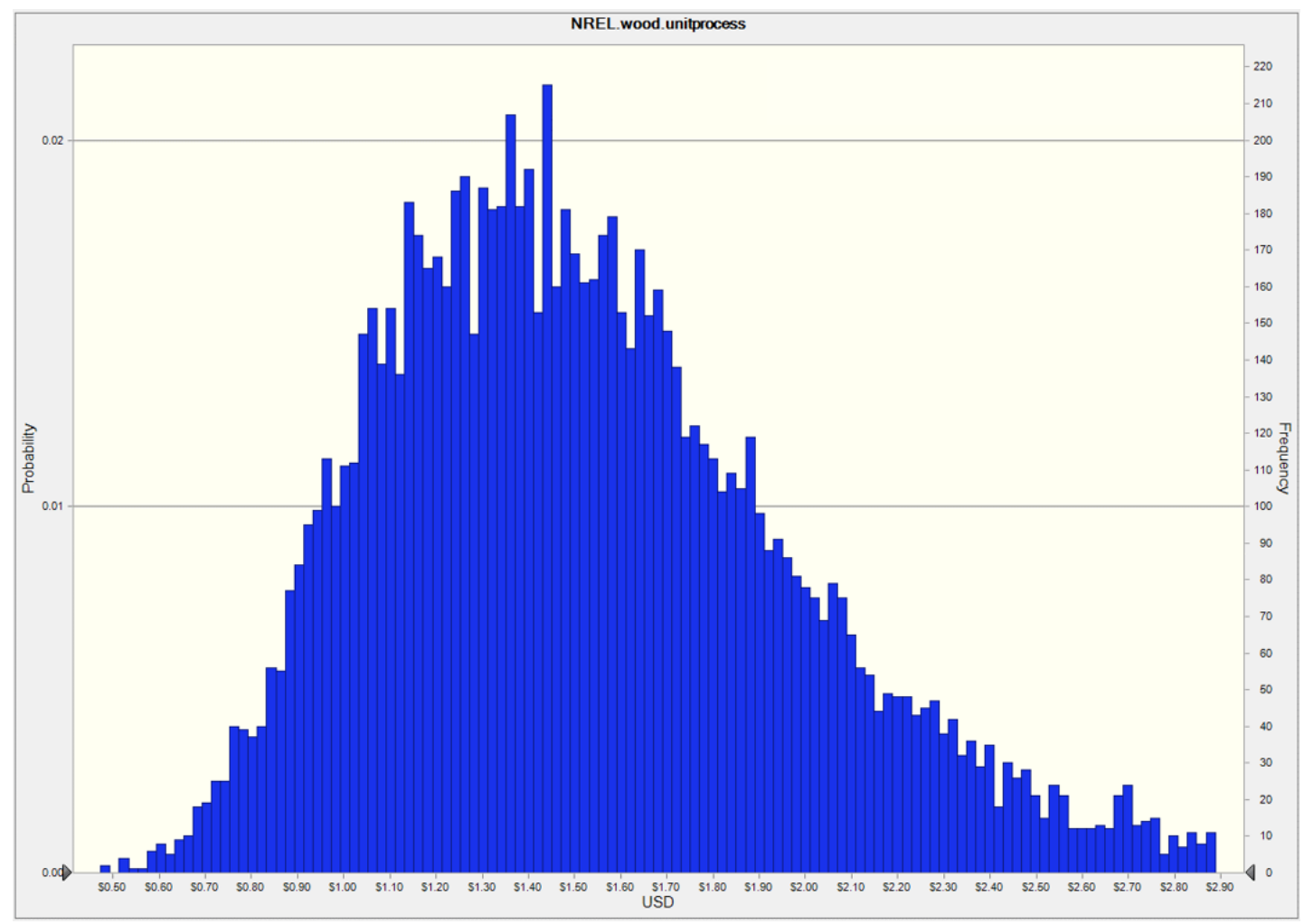

Fig. S2. CCA treated wood highway guardrail post damage cost distribution (source: NREL 2012; boundary condition: unit process) 


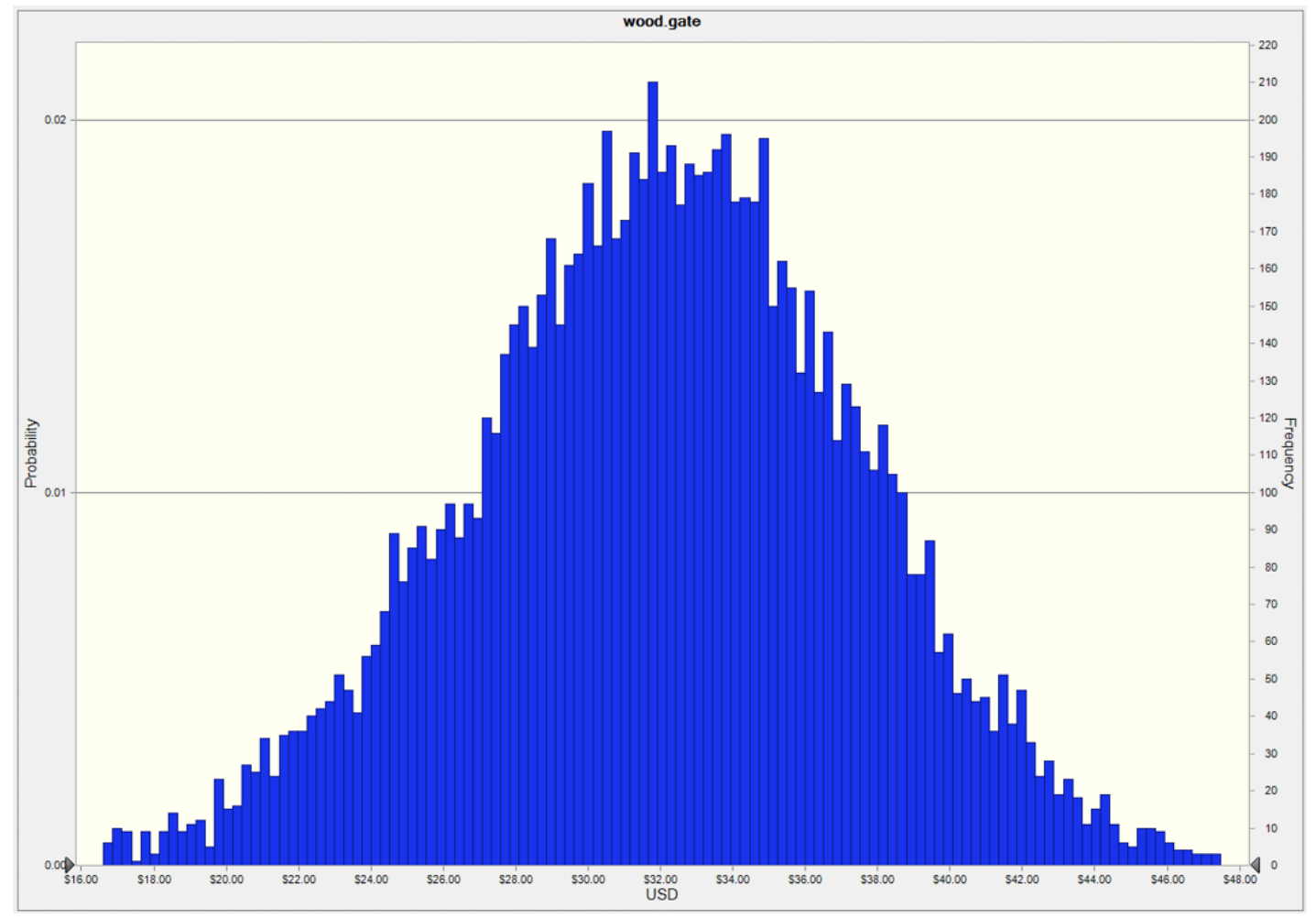

Fig. S3. CCA treated wood highway guardrail post full-cost price distribution (source: Bolin \& Smith 2012; boundary condition: cradle-to-gate)

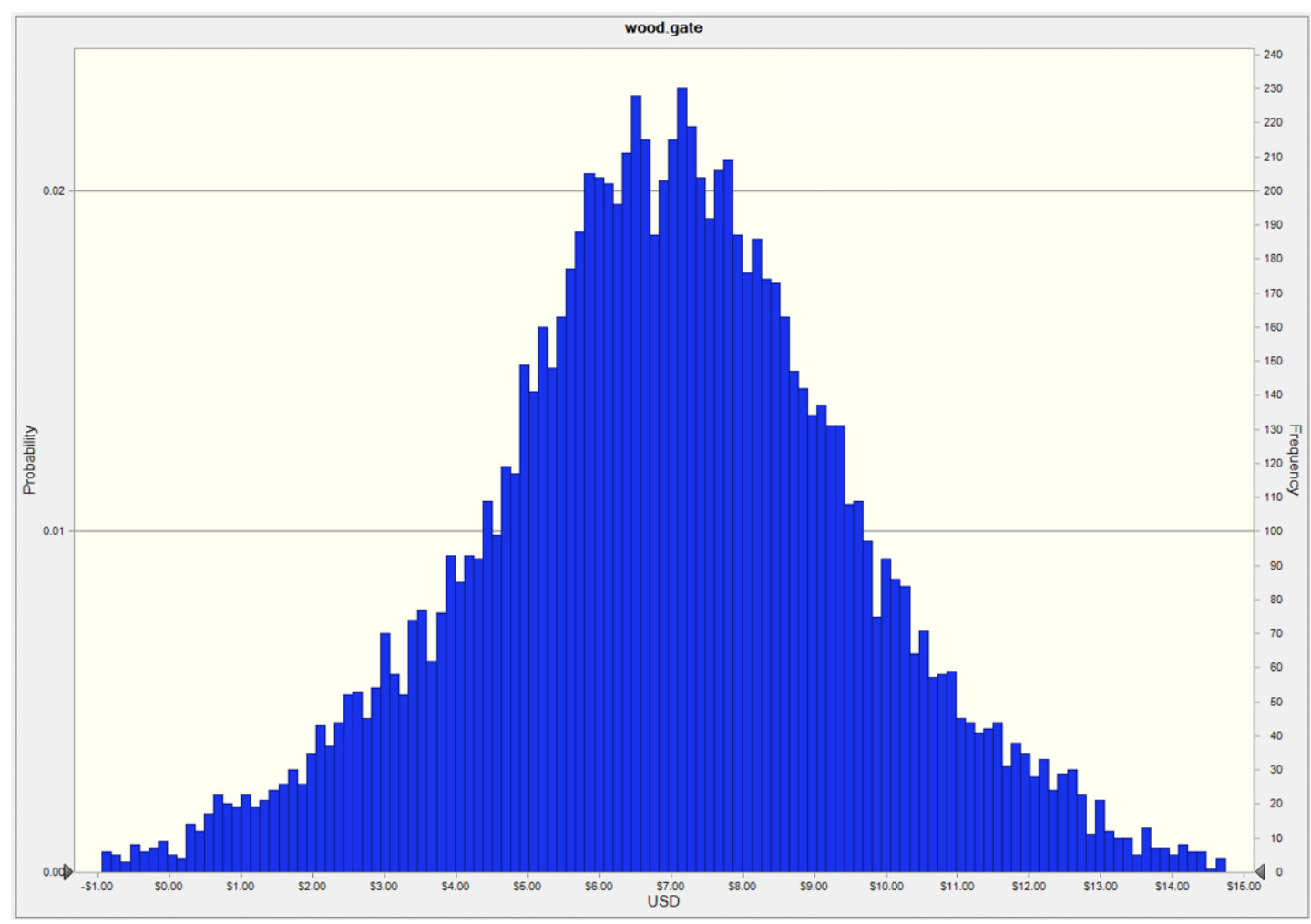

Fig. S4. CCA treated wood highway guardrail post damage cost distribution (source: Bolin \& Smith 2012; boundary condition: cradle-to-gate) 


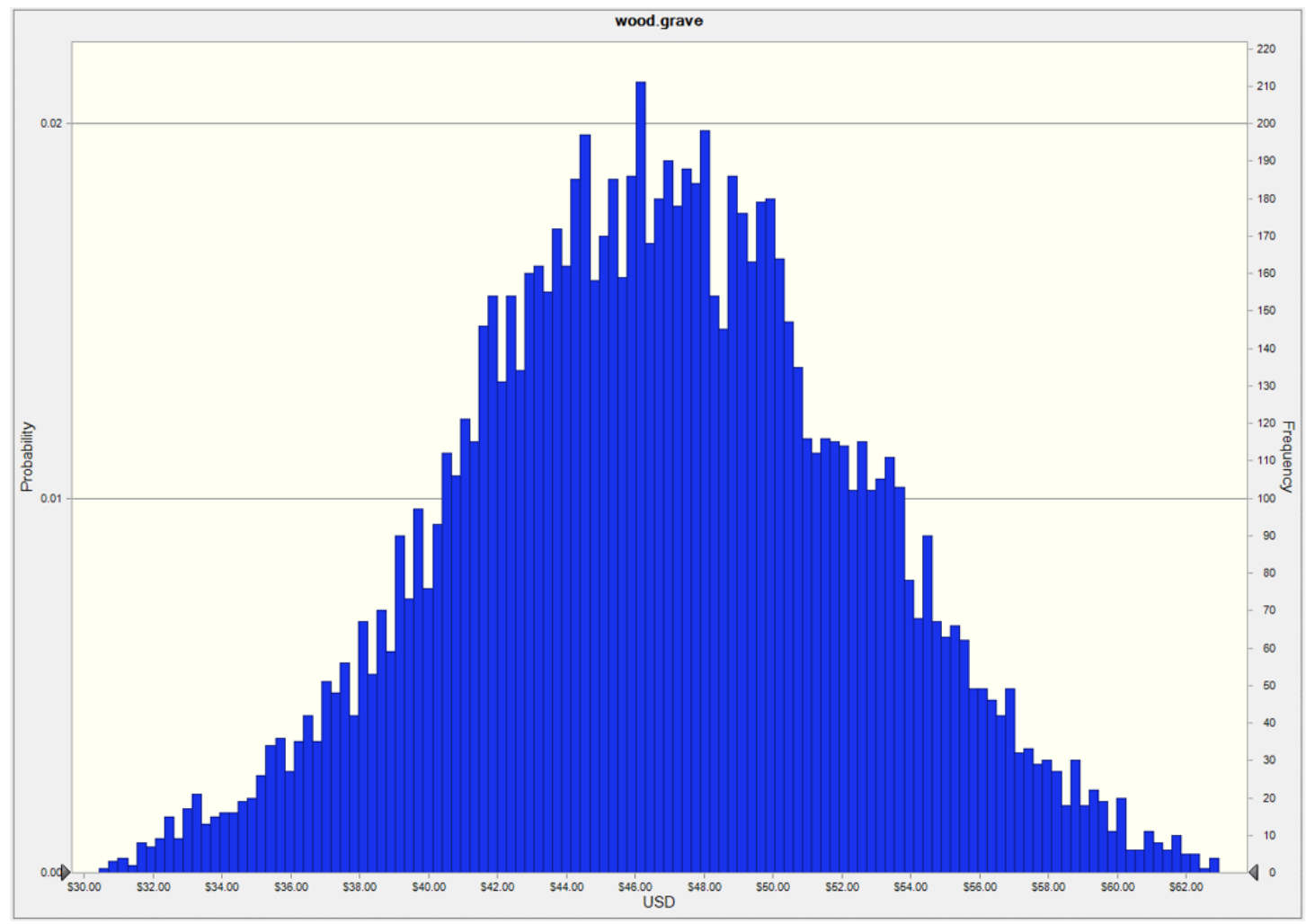

Fig. S5. CCA treated wood highway guardrail post full-cost price distribution (source: Bolin \& Smith 2012; boundary condition: cradle-to-grave)

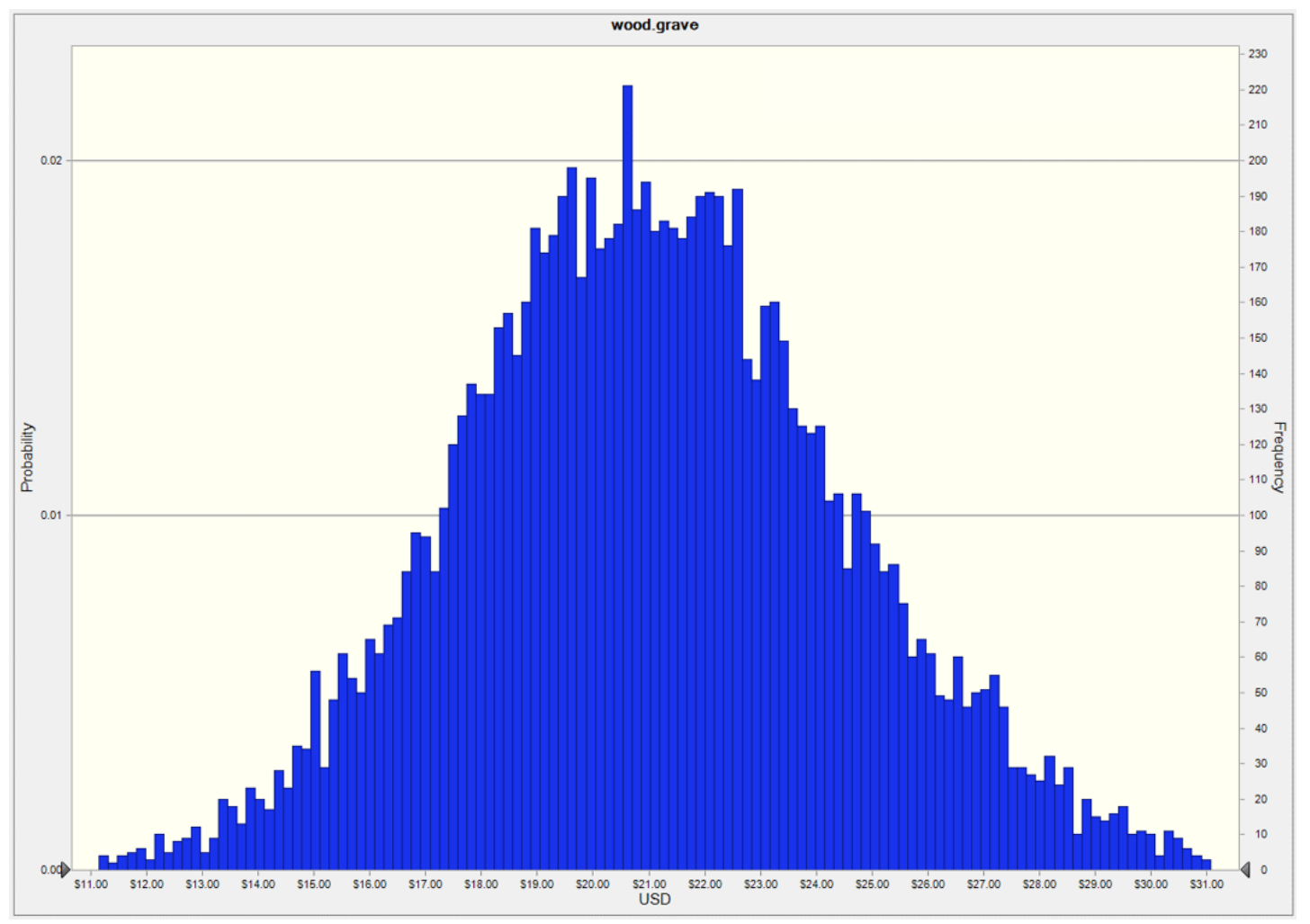

Fig. S6. CCA treated wood highway guardrail post damage cost distribution (source: Bolin \& Smith 2012; boundary condition: cradle-to-grave) 


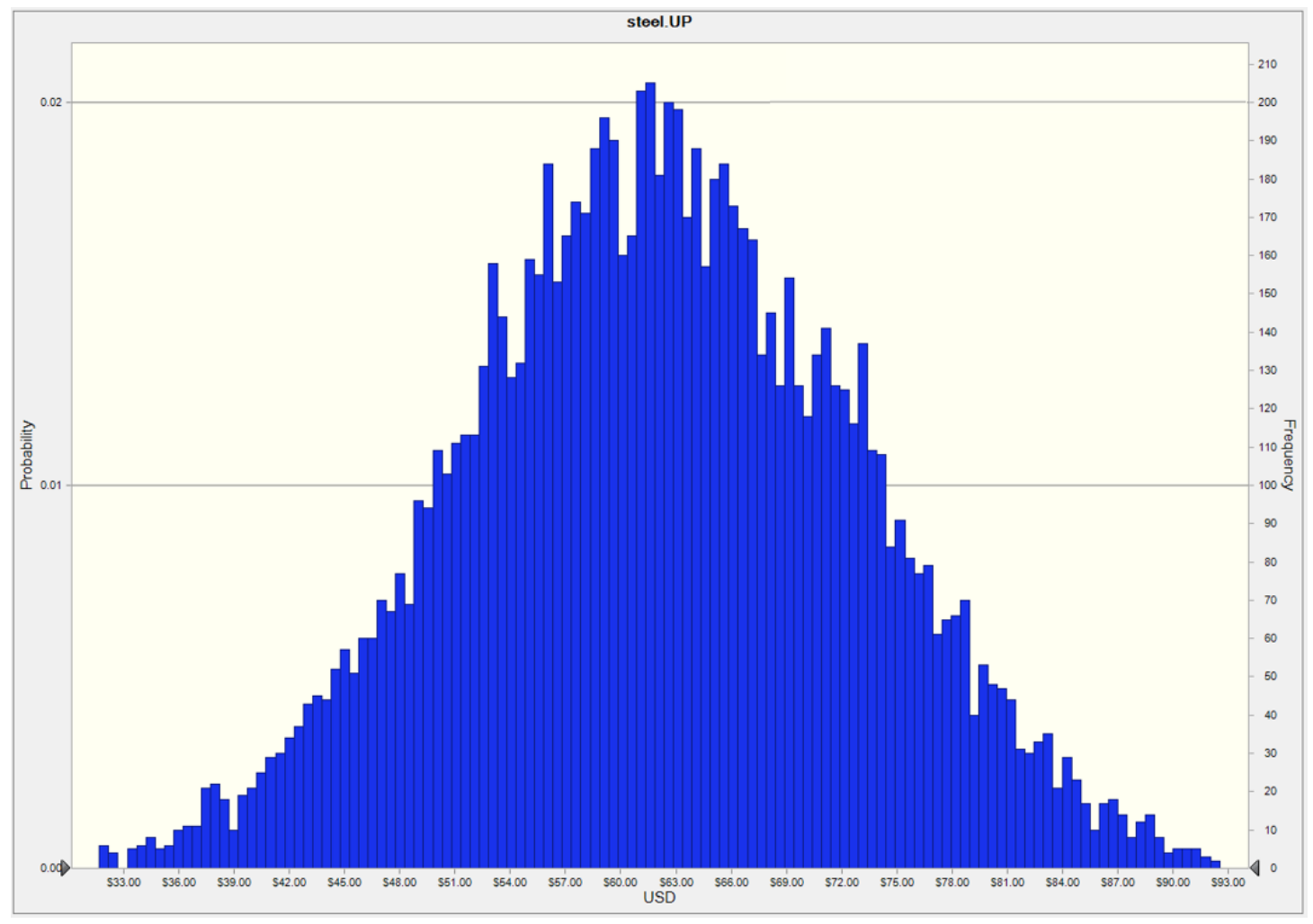

Fig. S7. Galvanized steel highway guardrail post full-cost price distribution (source: NREL 2012; boundary condition: unit process)

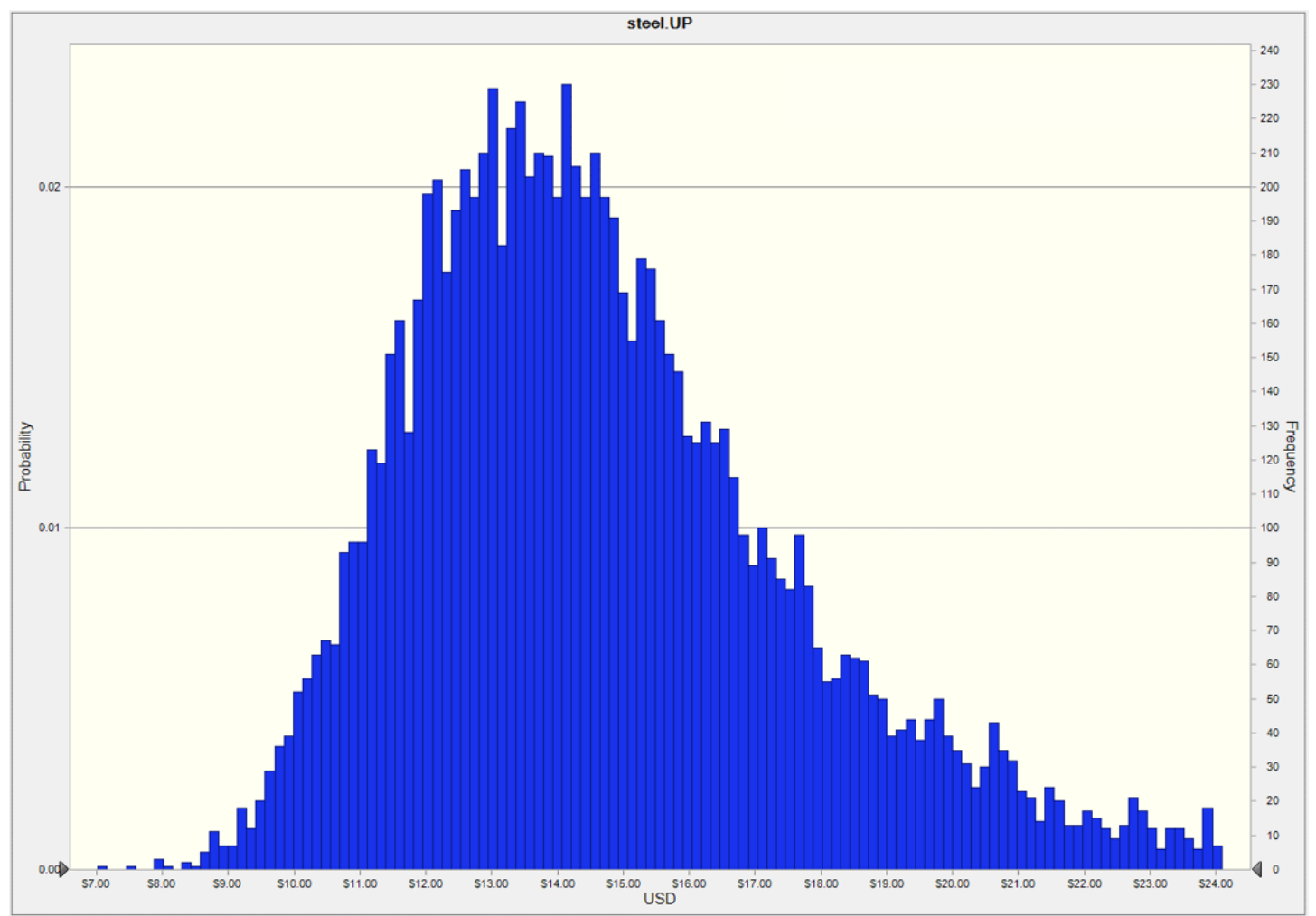

Fig. S8. Galvanized steel highway guardrail post damage cost distribution (source: NREL 2012; boundary condition: unit process) 


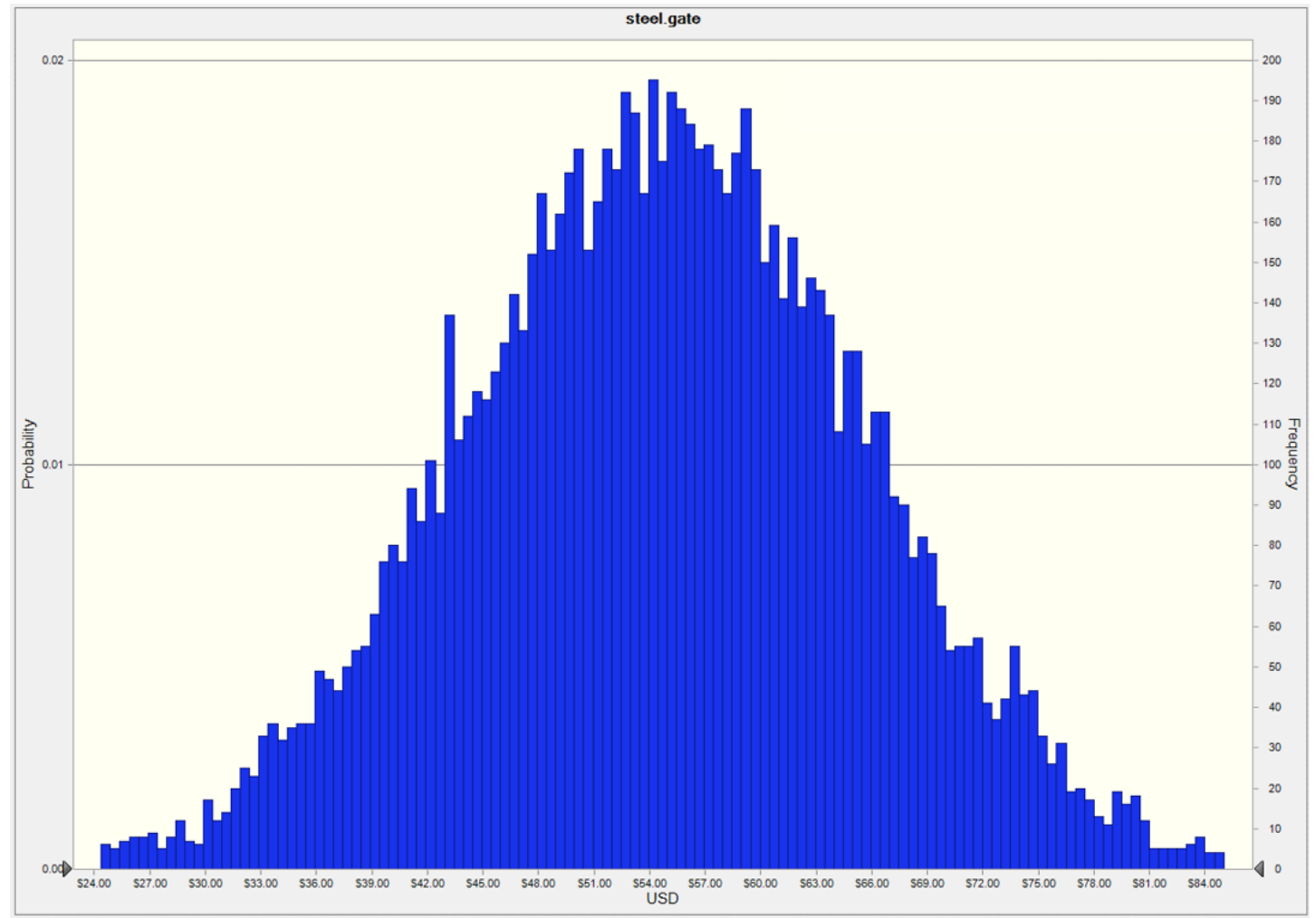

Fig. S9. Galvanized steel highway guardrail post full-cost price distribution (source: Bolin \& Smith 2012; boundary condition: cradle-to-gate)

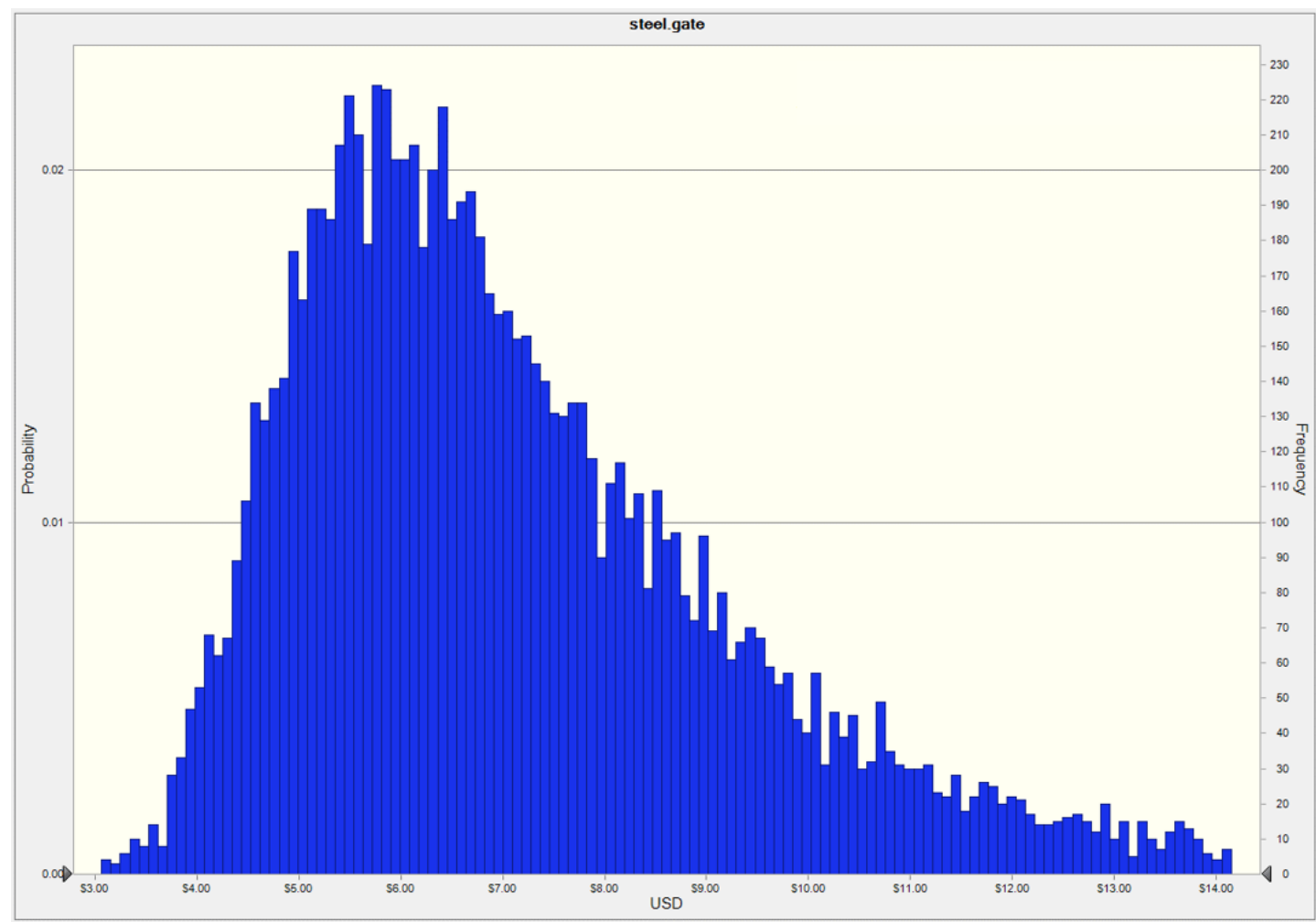

Fig. S10. Galvanized steel highway guardrail post damage cost distribution (source: Bolin \& Smith 2012; boundary condition: cradle-to-gate) 


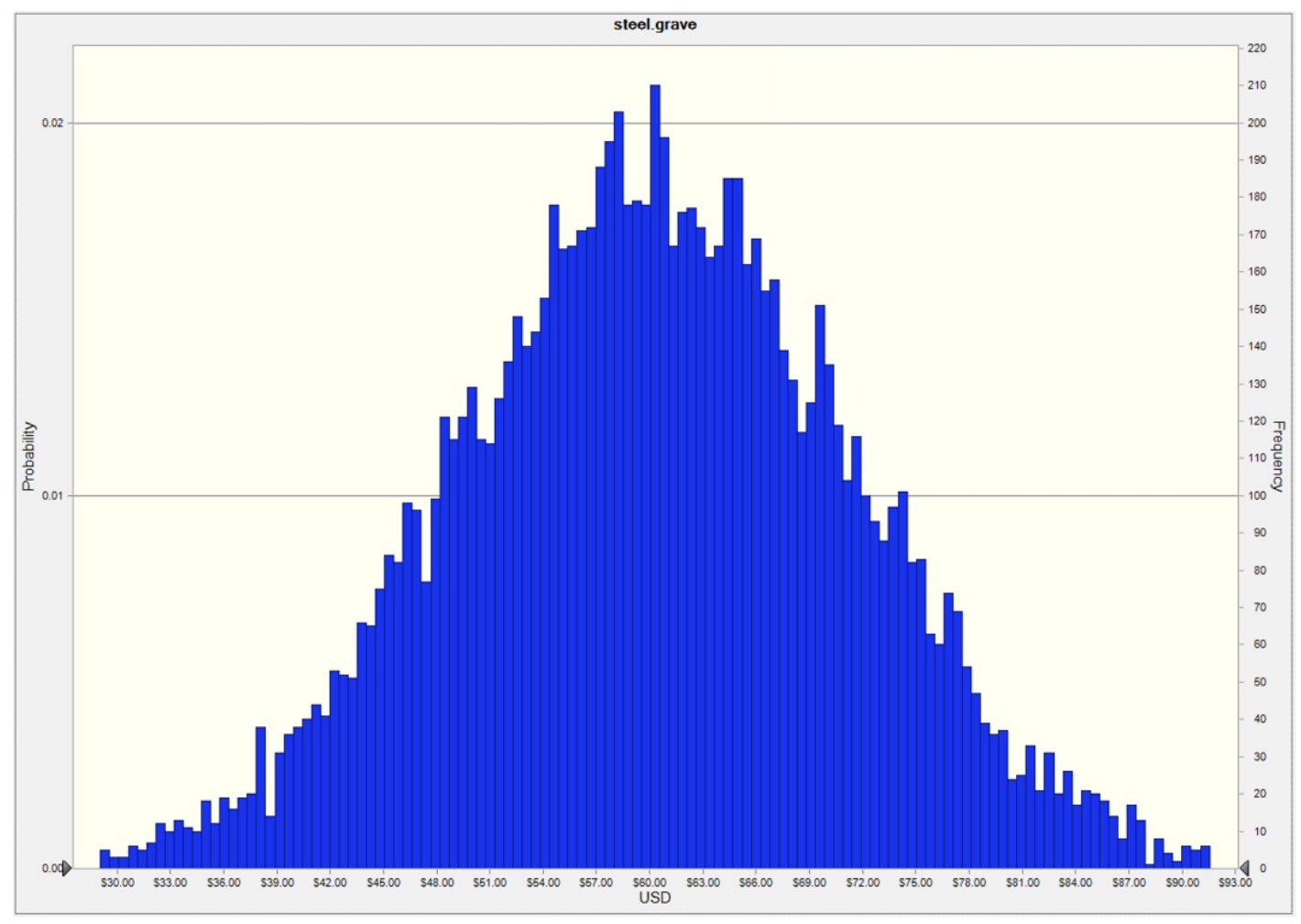

Fig. S11. Galvanized steel highway guardrail post full-cost price distribution (source: Bolin \& Smith 2012; boundary condition: cradle-to-grave)

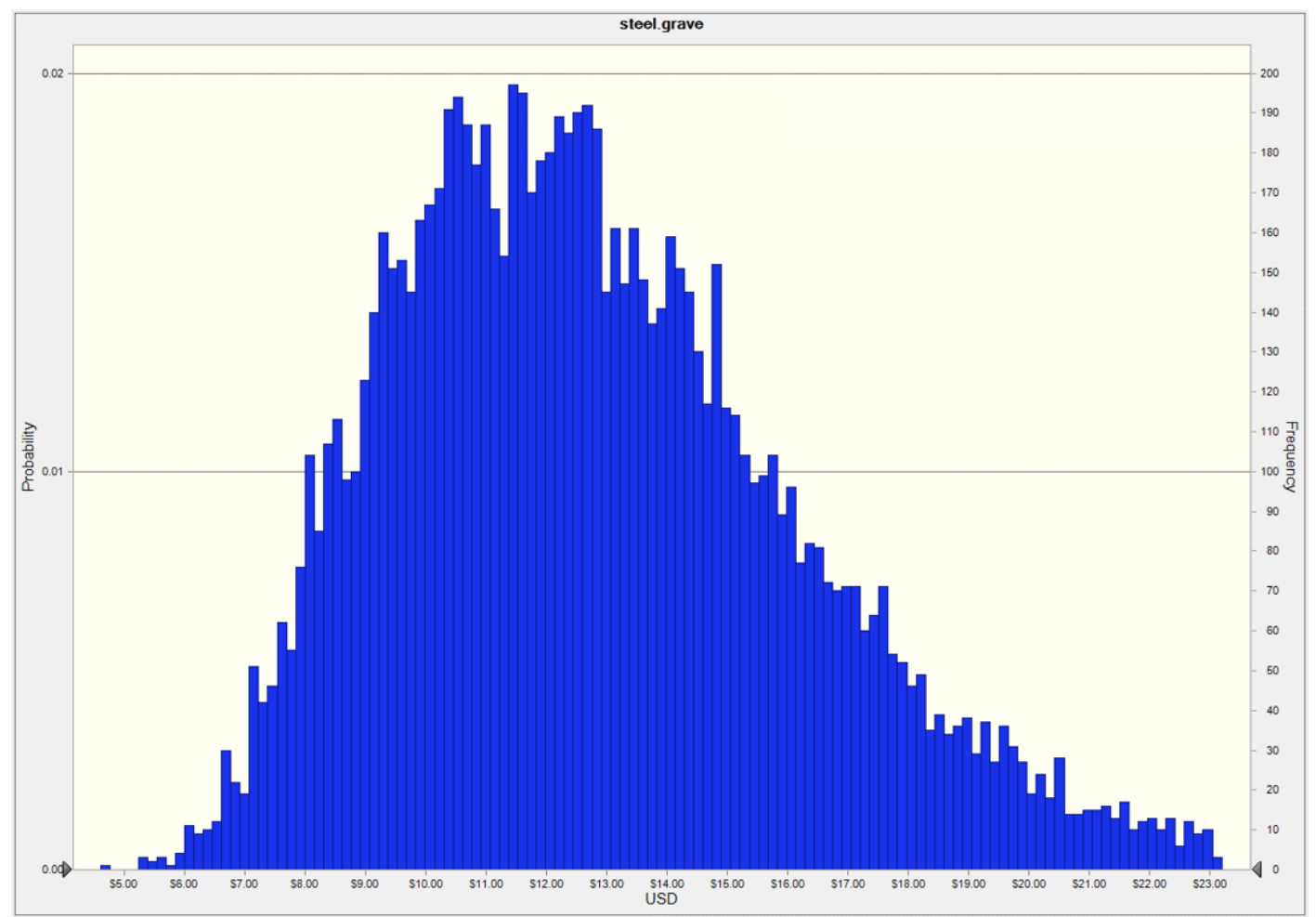

Fig. S12. Galvanized steel highway guardrail post damage cost distribution (source: Bolin \& Smith 2012; boundary condition: cradle-to-grave) 